\title{
La cerámica común del campamento romano de Cidadela (Sobrado dos Monxes, A Coruña).
} Campaña 2007

The common pottery from the Roman camp of Cidadela

(Sobrado dos Monxes, A Coruña). Campaign 2007

\section{Sara Barbazán Domínguez}

Departamento de Historia I. Universidade de Santiago de Compostela sarabzn@gmail.com

\section{José Manuel Caamaño Gesto}

Departamento de Historia I. Universidade de Santiago de Compostela

\section{Hugo Lozano Hermida}

Departamento de Historia I. Universidade de Santiago de Compostela

\section{Eduardo Ramil Rego}

Museo de Prehistoria e Arqueoloxía de Vilalba (Lugo)

\section{Resumen}

En este artículo estudiamos una colección cerámica que consideramos representativa de este asentamiento militar romano. Para ello utilizamos una metodología formal de ámbito regional con la que hacemos una clasificación tipológica. De esta forma, su análisis formal y tecnológico permite ponerla en relación con las producciones documentadas en la capital del Conventus, Lucus Augusti.

\section{Palabras clave}

Cerámica común romana, campamento militar, Antiguo Imperio Romano, Noroeste de la Península Ibérica.

\begin{abstract}
In this paper, we study a collection of pottery that we consider representative from this roman military settle. For this, we used a regional ambit formal methodology. This way, their formal and technological analysis allow linking them with the productions documented in the capital of the Conventus, Lucus Augusti.
\end{abstract}

\section{Key words}

Roman common pottery, military camp, Early Roman Empire, northwest of Iberian Peninsula.

\footnotetext{
Data de envío: 22-10-2014 Data de aceptación: 15-01-2015
} 


\section{INTRODUCCIÓN}

Cidadela es uno de los yacimientos romanos gallegos mejor conocidos, tanto por las numerosas campañas de excavación que en él se realizaron como por la multitud de trabajos publicados. No obstante, todavía no se ha prestado debida atención a uno de los materiales más abundantes dentro de los recuperados en el campamento, la cerámica común romana.

No debe perderse de vista, a la hora de enfrentarnos con este material, las dificultades expresadas por Huguet Enguita (2013), el término "cerámica común" fue, durante muchos años, un cajón de sastre en el que se solía incluir todas las cerámicas que no eran vajilla fina, ánforas o lucernas; es decir, todas aquellas piezas que no se podían encajar en otros grupos. Más allá de su poca precisión cronológica, la importancia del estudio de la cerámica común reside en la información indirecta que conlleva sobre los gustos, usos y costumbres culinarias y su variación temporal y espacial. Además aporta nociones de comercio de pequeña a gran escala, así como sobre las técnicas de fabricación y artesanado que creó cada producción concreta (HUGUET ENGUITA 2013: 296).

Con el fin de llevar a cabo un estudio homogéneo, coherente y centrado, que nos permitiese alcanzar los objetivos planteados hemos seleccionado, de la cerámica común recuperada en la campaña de 2007 , la procedente de la estructura denominada inicialmente como Horrea, descartando otros conjuntos heterogéneos de menor entidad y escasa representatividad.

\section{LOCALIZACIÓN Y CARACTERÍSTICAS DEL YACIMIENTO}

El yacimiento se localiza (Fig.1) en el entorno inmediato a la Iglesia parroquial de Santa María de Ciadella, Concello de Sobrado dos Monxes, provincia de A Coruña. Su situación geográfica se corresponde con las siguientes coordenadas, según ED50, HUSO29, X 579.774, Y 4.756.978 y Z 483. Su ubicación se encuentra en el margen occidental de la meseta de Lugo en conexión con las mariñas costeras del litoral coruñés. En esta localización tenemos un paisaje donde se alternan sistemas montañosos de escasa altura con altiplanicies y valles poco profundos.

Las primeras noticias se remiten a principios del siglo XX, cuando García Romero (1909a) localiza los restos de un yacimiento que llega a identificar con Caranico, mansión viaria de la vía XX per loca marítima que, según el Itinerario de Antonino, se ubica en el tramo Brigantium-Lucus Augusti (CAAMAÑO GESTO 1984: 238). De modo oficial, las excavaciones en el yacimiento fueron iniciadas por A. del Castillo en 1934, con la colaboración de Sebastián González, siendo el primero en identificar el yacimiento como un campamento romano. Sin embargo, no será hasta la década de los 80 cuando será sistemáticamente excavado de la mano del Prof. Caamaño Gesto y su equipo de la Universidad de Santiago (CAAMAÑO GESTO, FERNÁNDEZ RODRÍGUEZ 2002), continuando las campañas durante la primera década del s. XXI.

La forma general del campamento es la de un espacio rectangular, con las esquinas redondeadas. Sus dimensiones son $172 \mathrm{~m}$ de largo por $140 \mathrm{~m}$ de ancho, lo que equivale 
a una extensión total de 2, 40 ha, medidas adecuadas para el asentamiento de una cohorte. El hallazgo de alrededor de 300 tégulas con marcas legionarias, los testimonios epigráficos, y las fuentes escritas clásicas como la Notitia Dignitatum $(42,30)$ han permitido identificar a la unidad aquí establecida con la Cohors I Celtiberorum. Su presencia se documenta a finales del siglo I d.C. en el Norte de Africa (Maruritania) y a principios del siglo II d.C. ya en Cidadela donde permanece hasta el siglo IV, momento en que es trasladada a Iuliobriga (Reinosa-Santander).

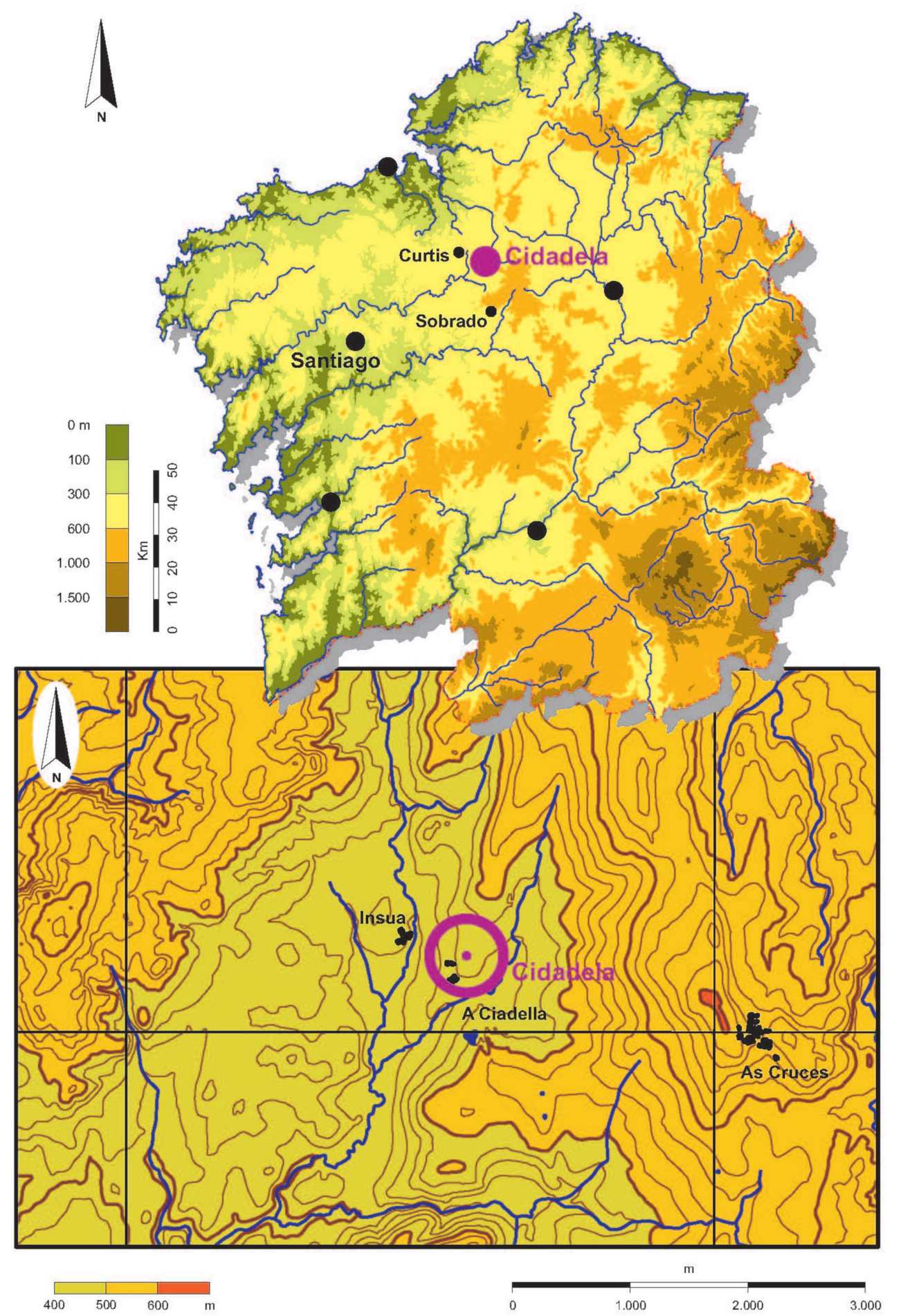

Figura 1. Localización geográfica del campamento romano de Cidadela (Sobrado dos Monxes, A Coruña). 


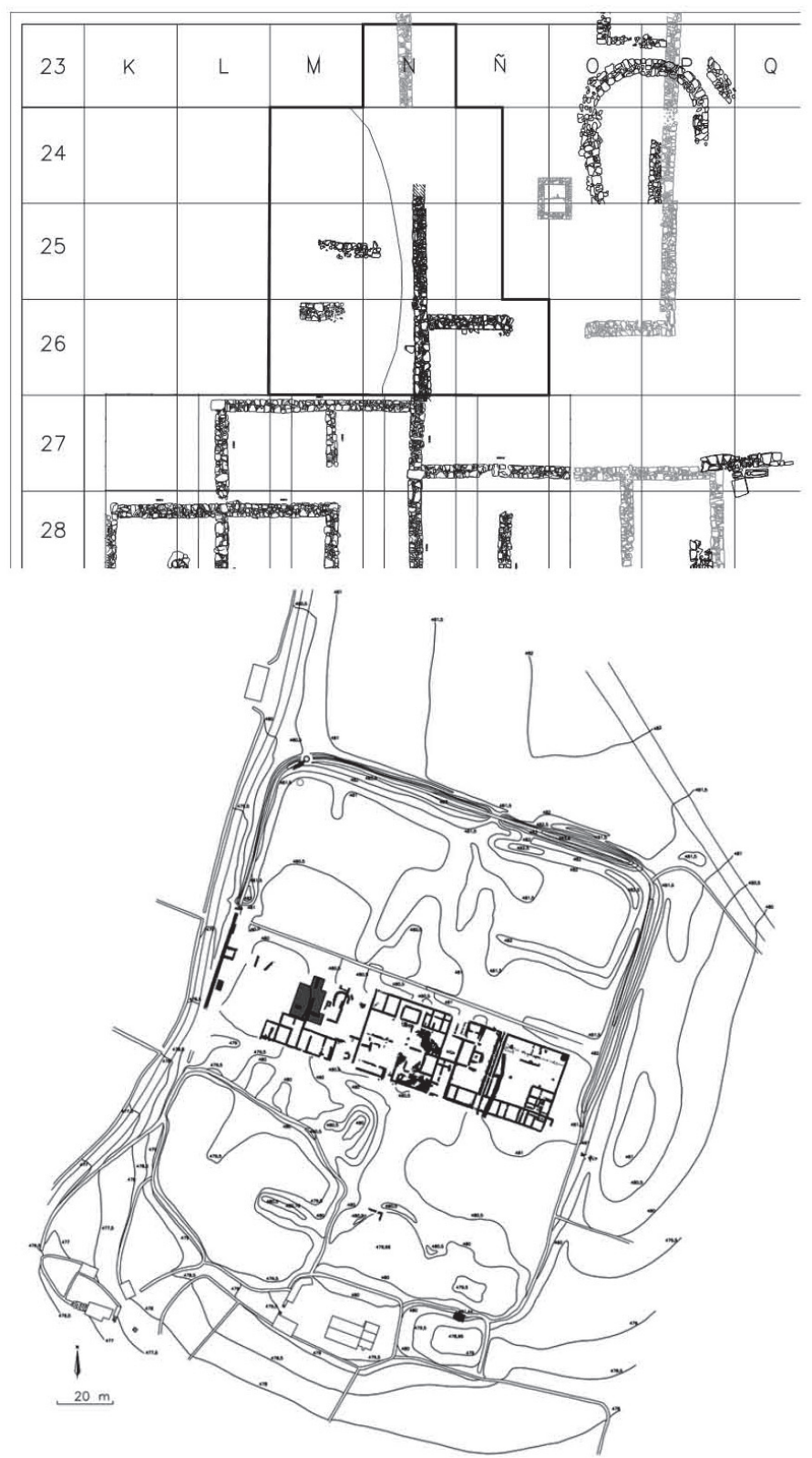

Figura 2. Planimetría del sector de los Horrea y del yacimiento de Cidadela durante la campaña del 2007 (Ramil González, 2007).
Se han constatado escasos fragmentos de TSAD y TSFT, datadas entre el siglo IV y el siglo V-VI, que podrían indicar un posible poblamiento residual tras el abandono, pero teniendo en cuenta las amplias cronologías de estas cerámicas y que estos restos, junto con los escasos ejemplares de ánforas palestinas, o los vidrios de los tipos Isings 67 o 96, constituyen las únicas evidencias dentro de Cidadela que indican la posible existencia de este poblamiento (LÓPEZ PÉREZ, 2006: 437), consideramos esta hipótesis poco probable por el momento, hasta que futuras investigaciones aporten nuevos datos. Con posterioridad, en el s. VII, el yacimiento será nuevamente ocupado por una población civil germánica que destruye o reaprovecha los muros romanos para adaptarlos a su urbanismo (CAAMAÑO GESTO et al. 2000: 282).

Durante la campaña del 2007 se realizó una intervención sobre una zona situada

a la izquierda del Principia, limitada al sur por la Via Principalis y al oeste por el Intervallum. De ahí se delimitaron un conjunto de estancias distribuidas en torno a un patio, de donde proceden las cerámicas objeto de nuestro estudio (Fig.2). La primera de estas construcciones muestra una planta en la que dos cuerpos rectangulares de desigual tamaño -23,75 x 29,6 y 13,50 x 7,40 m respectivamente- adoptan una forma similar a la de una L. En su interior, un gran patio ocupa el espacio central, manifestándose sólo en el ámbito meridional trazas de compartimentación del espacio en habitáculos rectangulares de diferente tamaño que contarían a su vez con una buena pavimentación. El acceso al edificio se produciría por el espacio central del lienzo sur, desde la Via Principalis, documentándose aquí los restos de un antiguo pavimento elaborado en opus signinum y evidencias de una entrada (RAMIL GONZÁLEZ et al., 2013: 272). 
De acuerdo con el patrón de distribución se pensó entonces que en la parte occidental debían encontrarse los Horrea o silos, de ahí la denominación inicial de este sector (RAMIL GONZÁLEZ 2007). Sin embargo, a día de hoy esta teoría está descartada, y se aboga por un posible uso como almacén debido a que la zona no presenta señales de habitabilidad. Su funcionalidad seguirá siendo complicada mientras no se avance en el conocimiento general del urbanismo campamental (RAMIL GONZÁLEZ et al. 2013: 272).

El estudio de este campamento y de los materiales hallados en él se encuentra en una fase avanzada. En este sentido debemos destacar el trabajo de López Pérez (2006) para la terra sigillata, en paredes finas a López Pérez y Caamaño Gesto (2011), en vidrio a Vázquez Martínez (2000) y Caamaño Gesto (1990) y a Carlsson-Brandt Fontán (2011) para el material de construcción latericio. Como precedente de nuestro estudio, cabe destacar el trabajo de Doval Galán (1990) respecto a la cerámica común. Con otro enfoque más recopilatorio y divulgativo cabe mencionar el trabajo de Costa García (2013).

\section{Metodología}

La ausencia de hornos de producción alfarera en Cidadela nos lleva a suponer que la cerámica objeto de nuestro estudio debe proceder de otro centro de producción. Teniendo en cuenta que el yacimiento se ubica en el entorno de Lucus Augusti, el foco de romanización más importante del Norte con una actividad alfarera constatada hemos establecido como hipótesis de partida para el origen de nuestra colección la relación entre la ciudad y el campamento. Apuntala este razonamiento la existencia de colecciones similares a las lucenses en yacimientos de la costa cantábrica y el occidente asturiano (HEVIA GONZÁLEZ et al. 200o).

Partiendo de esta hipótesis, hemos escogido la tipología de Alcorta Irastorza para Lugo (2001) para realizar el estudio de esta colección teniendo en cuenta sus descripciones formales y la cronología establecida por él para los diferentes tipos (Fig.3). Esta tipología se construye en principio partiendo de un criterio formal al que se suman otros de índole tecnológica, funcional y decorativa. Sin embargo, la formulación de los tipos no siempre responde a esta jerarquización, lo que dificulta su aplicación práctica y suscita problemas de adscripción. Pese a ser conscientes de sus limitaciones la asumimos por ser la más utilizada y la única que nos permitiría comparar ambos conjuntos, y a su vez estos con los de otros lugares donde ha sido aceptada.

Para identificar algunos fragmentos que no encajan en esta tipología hemos recurrido a Vegas (1973) porque, pese a ser la tipología de la que parte Alcorta (2001), su definición de tipos no es tan restrictiva como la de este último.

Como estas tipologías no permiten explicar la totalidad de nuestra muestra, hemos acudido al estudio realizado en el campamento de Rosinos de Vidriales en Zamora (CARRETERO VAQUERO 200o) por la semejanza formal y cronológica de sus grupos cerámicos con los nuestros, y también a los estudios realizados en Chao Samartín (HEVIA GONZÁLEZ et al. 2000), por los mismos motivos. 


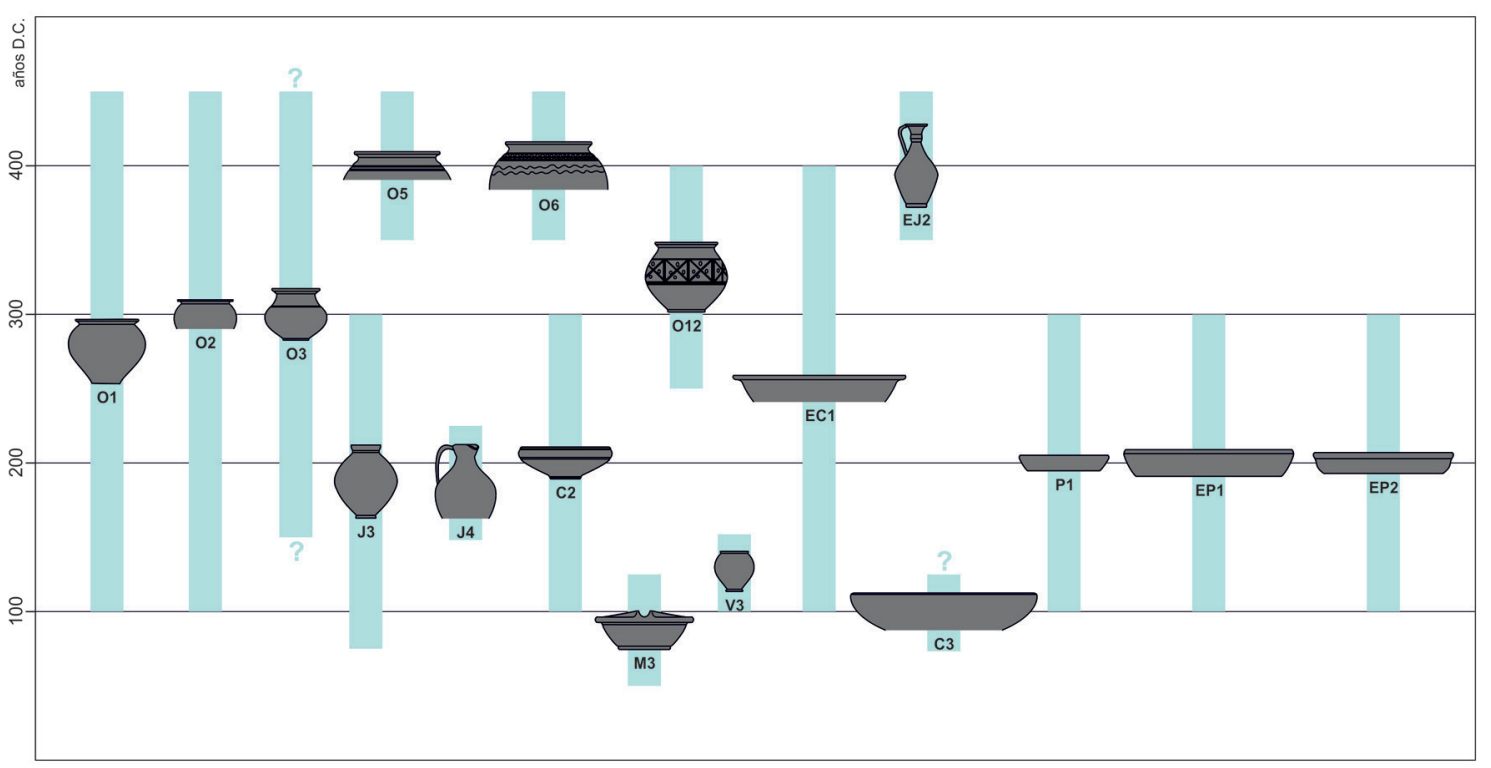

Figura 3. Cuadro cronológico de los tipos presentes en Cidadela según los datos de Alcorta (2001) para Lugo.

Pese a todo, existen algunos fragmentos que no hemos podido identificar debido a que no encajan en ninguno de los conjuntos arriba mencionados al presentar formas que difieren de los tipos de referencia, y distinta tecnología en cuanto a pastas, tratamiento y decoración. Los presentamos aquí en aras de que posteriores estudios nos aclaren su incógnita.

\section{ESTUDIO DEL MATERIAL}

Dentro de la colección del 2007, nos encontramos con que el total de piezas asciende a 1.338. Dentro de este grupo, hemos seleccionado aquellas piezas que por sus características morfológicas o decorativas podrían ser de relevancia para la fase de análisis. Finalmente nos hemos quedado con un total de 267 piezas que hemos registrado individualmente en una base de datos.

Desde un punto de vista general, estamos ante una cerámica que presenta una acusada fragmentación. Del total de la muestra analizada, solo dos piezas han presentado el perfil entero (Fig. 7 y 15.3) el resto del material se componía de fragmentos con poco o escaso desarrollo.

\section{Descripción de los tipos identificados}

\section{Servicio de cocina}

\section{Ollas}

Este grupo es el mejor representado dentro de la colección, predominando las ollas de cuerpo globular y borde exvasado oblicuo. En general nos encontramos con ollas cuyas dimensiones varían de los 15 a los $25 \mathrm{~cm}$ de diámetro de borde, que presentan pastas grises o negras y acabados toscos y poco cuidados. Carecen de decoración, salvo algunos casos excepcionales. 
Dentro de esta selección, el tipo mejor representados sería el O1/O1A, definido como ollas globulares de borde exvasado oblicuo, sin decoración. En nuestra muestra tendríamos, por un lado, las O1 (Fig. 4, 1-2) de entre 19 y $22 \mathrm{~cm}$ de apertura de borde, y por otro la O1A (Fig.4, 3-5) con unos diámetros que irán desde los 14 a los $19 \mathrm{~cm}$ de apertura de borde. Ambas series se caracterizan por presentar bordes exvasados oblicuos, predominando los labios apuntados y redondeados, y por carecer de decoración, salvo

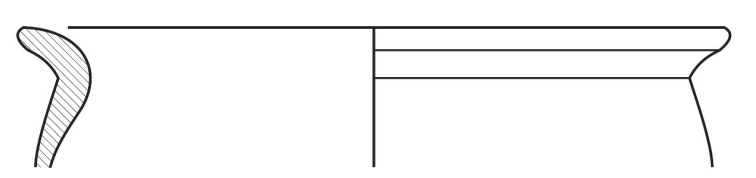

1
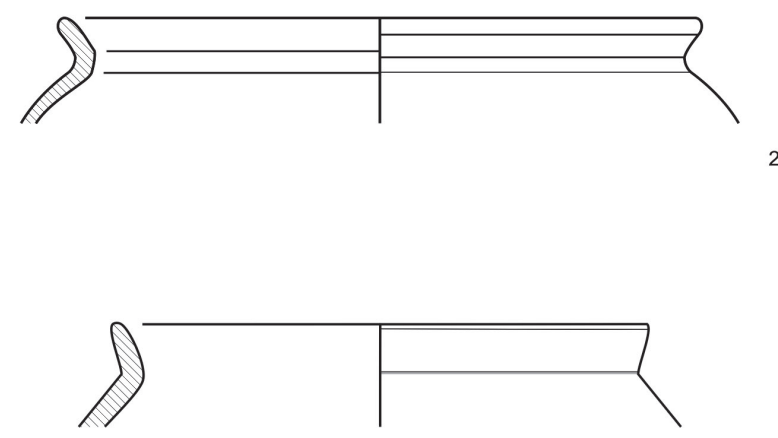

3
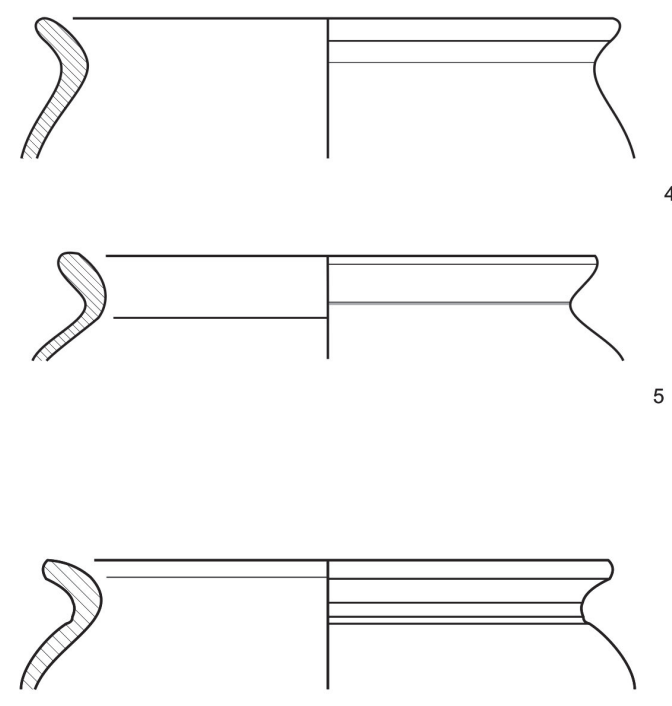

6

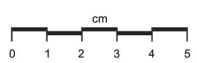

Figura 4. Ollas globulares de borde exvasado oblicuo, sin decoración. Tipo 01 (1-2)/tipo 01A (3-5). Ollas de cuerpo globular y borde vuelto, con acanaladuras. Tipo 05 (6). se mueven, en general, entre los 14 y los $17 \mathrm{~cm}$ de apertura de borde, presentando bordes curvos que acaban en labios redondeados (Fig. 5.1 y 5.3) o rectos (Fig. 5.2). En lo referente a las pastas, estas presentan gran similitud con las O1/O1A, moviéndose entre el negro y alguna leve incisión (Fig.4.3). En ambas las pastas se mueven entre tonalidades negras y grisáceas, presentando la misma gama tonal en el exterior. En general, son recipientes toscos y rugosos, con abundantes desgrasantes de mica y cuarzo y en los cuales predominan los alisados.

Se considera que el uso de estas vasijas es longevo, empleándose como recipiente básico del servicio de cocina desde principios del siglo II d.C. hasta mediados de la quinta centuria, reconvertidas en época bajoimperial en el tipo O5 (Fig.4.6), similares a las anteriores pero con presencia de decoración de acanaladuras en la parte superior de la panza. Predomina la presencia de restos de quemado y carbonización. Su elevado número indica que estas principales recipientes empleados para las tareas de cocina $\mathrm{y}$ preparación de alimentos.

Respectoaltipo O2(Fig.5, 1-3), ollas globulares de borde curvo, sin decoración; hay que destacar que este es uno de los grupos más representativos después del citado O1/O1A. Sus dimensiones ollas debieron ser uno de los 

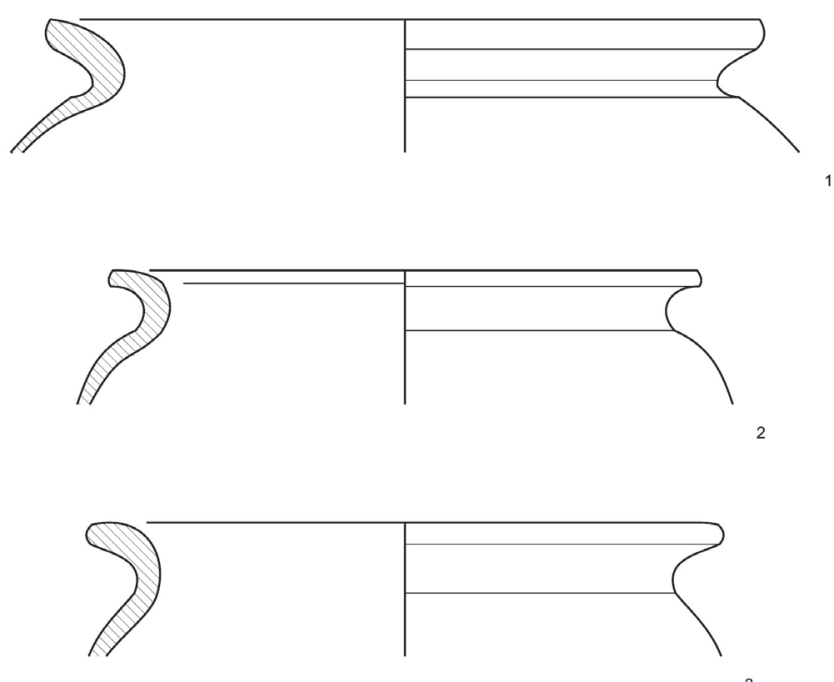

3
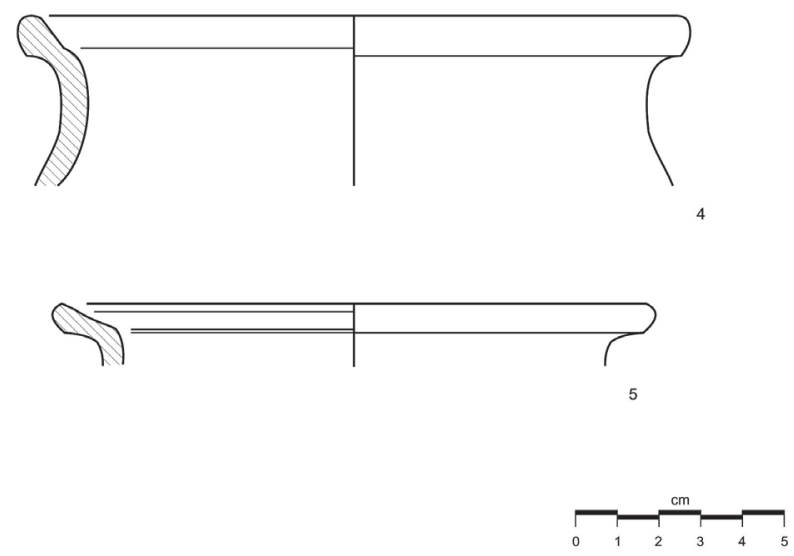

Figura 5. Ollas globulares de borde curvo, sin decoración. Tipo 02 (1-3). Ollas monoansadas de perfil sinuoso, borde cóncavo, sin decoración. Tipo O3 (4-5). el gris claro. El exterior presenta la misma gama tonal. Están alisadas y carecen de decoración, salvo algunas incisiones aisladas. $\mathrm{Al}$ igual que las anteriores, presentan restos de carbonización.

Por último, en el apartado de las ollas cabría destacar aquí el tipo $\mathrm{O}_{3}$ (Fig.5, 4-5), definido como un grupo de ollas monoansadas de perfil sinuoso, borde aconcavado, sin decoración. Respecto a este apartado, no contamos para esta campaña con ejemplos que sigan fielmenteesta definicióntipológica, debido a que el escaso desarrollo de las piezas no ha mostrado indicios de asa. Sin embargo, tenemos varios fragmentos de borde que, al margen de este criterio del asa, que creemos poco acertado, responden bastante bien a este esquema $\mathrm{y}$ que, por sus dimensiones, quedan fuera del tipo O15, también de borde cóncavo pero con una factura muy fina y cuidada, y grandes dimensiones $(25-30 \mathrm{~cm}$ de diámetro de boca).

Así pues tenemos una muestra poco representativa, de tan solo unos pocos fragmentos (Fig.5, 4-5), que presentan un borde exvasado oblicuo, cóncavo en su parte interna y perfil sinuoso. Aunque carecen de asa, como ya hemos apuntado, su proximidad morfológica los hace susceptibles de ser clasificados dentro de este tipo, aunque un mayor desarrollo de las piezas podría permitir ajustar más esta identificación. Tendríamos para estos fragmentos unas dimensiones que estarían en torno a los 14-16 cm de diámetro de boca, y unas pastas coincidentes con las de la tipología presentada, siendo grises en casi toda la muestra. Su escaso número indica que su empleo fue, en todo caso, inferior al de las O1/O1A y O2. Su cronología aún no se ha podido precisar con seguridad.

\section{Ollas grandes}

Para este apartado, la aportación de la campaña del 2007 no es muy amplia, pero sí muy significativa. Los escasos ejemplos de ollas grandes, por su amplio desarrollo, nos aportan mucha información acerca de las características morfológicas y los esquemas 
decorativos de este tipo de cerámica, algo de lo que carecían las cerámicas anteriores. Dentro de este apartado cabría destacar el tipo O6 y el tipo O12/O12A.

Respecto al primero, el tipo O6, este es definido como grandes ollas globulares con decoración incisa ondulada, caracterizadas por presentar un fondo plano, cuerpo globular y borde exvasado curvo que remata en labios rectilíneos, apuntados o redondeados. Sin asas. Respecto a este grupo, al igual que sucedía con el tipo $\mathrm{O}_{3}$, no contamos entre nuestra muestra con ejemplos que sigan fielmente esta descripción tipológica, sin embargo, tres de nuestras piezas se podrían ajustar bastante bien a esta categoría (Fig.6, 1-3). A pesar de que carecen de decoración, su proximidad morfológica las hace susceptibles de ser integradas aquí, aunque un mayor desarrollo de mismas permitiría ajustar esto un poco más. Al igual que el tipo anterior, el $\mathrm{O}_{3}$ con el asa, consideramos que la inclusión del criterio decorativo a la hora de establecer una tipología puede resultar ambiguo y confuso, y más a la hora de enfrentarnos a una muestra de tan escaso desarrollo como la presente.
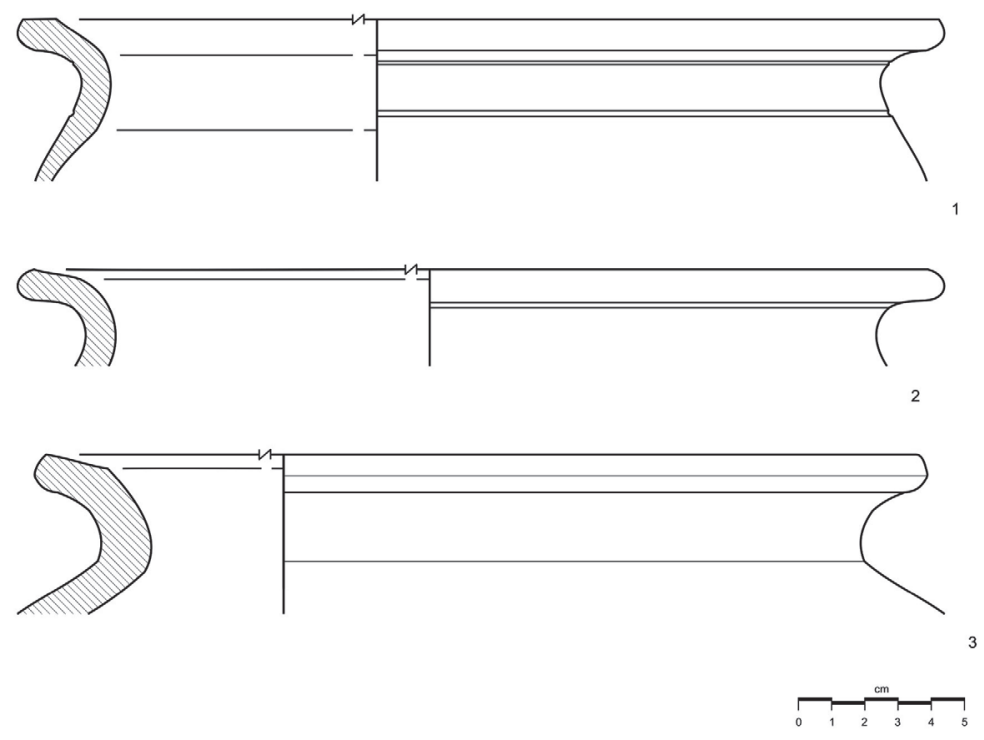

Figura 6. Grandes ollas globulares con decoración incisa ondulada. Tipo 06 $(1-3)$.

Así pues, este grupo presentaría un borde exvasado curvo, con labios rectilíneos o redondeados y arranque de cuerpo con indicios de ser globular, con un diámetro de boca que va de los 30 a los $38 \mathrm{~cm}$. De pastas grises y ocres y desgrasantes de mica y cuarzo presentan una superficie gris/parda sin trazas de tratamiento superficial, y con presencia de desgrasantes en la superficie, aunque podrían tener restos de un ligero alisado. Por su volumen deben tratarse de recipientes de almacenaje, aunque no se descarta su utilización marginal como olla de cocina dada la ocasional presencia de hollines en los exteriores (Fig.6.3).

Respecto al tipo O12A, este resulta ser uno de los grupos más interesantes debido a que posee una de las piezas más relevantes de la campaña del 2007. Este tipo es definido como grandes ollas globulares, grises, de borde exvasado y decoración espatulada. Sus medidas tendrían diámetros máximos en torno a los $30 \mathrm{~cm}$ y aperturas de borde sobre los $20 \mathrm{~cm}$. A pesar de que son incluidas dentro de las grandes ollas, los diámetros expuestos para las O12A, coinciden con los propuestos para las O1, consideradas ollas normales. 
Creemos que esto puede llevar a confusiones a la hora de incluir las piezas dentro de un tipo u otro.

Dentro de este tipo encontramos uno de los pocos fragmentos que presentan el perfil entero (Fig.7). Se trata de un recipiente de fondo resaltado, cuerpo globular, borde exvasado oblicuo y labio engrosado de sección triangular con frente superior plana. $\mathrm{Su}$ apertura de borde es de $20 \mathrm{~cm}$. Y su diámetro de base se sitúa entre los 9 y los 10 $\mathrm{cm}$. Presenta una pasta de color gris, micácea y depurada, y una superficie de color gris oscuro, bien alisada. Una de las principales características de esta pieza es su decoración, única dentro de la muestra analizada. Esta está formada por una sucesión de dos líneas acanaladas, situadas en la parte superior y la parte inferior de la panza respectivamente, que enmarcan un friso donde iría situada el resto de la decoración, formada por líneas bruñidas verticales y oblicuas que conforman una serie de motivos aspados. Por su volumen, calidad de elaboración y general ausencia de manchas de carbonización, su clasificación como ollas de almacenaje es aceptable.

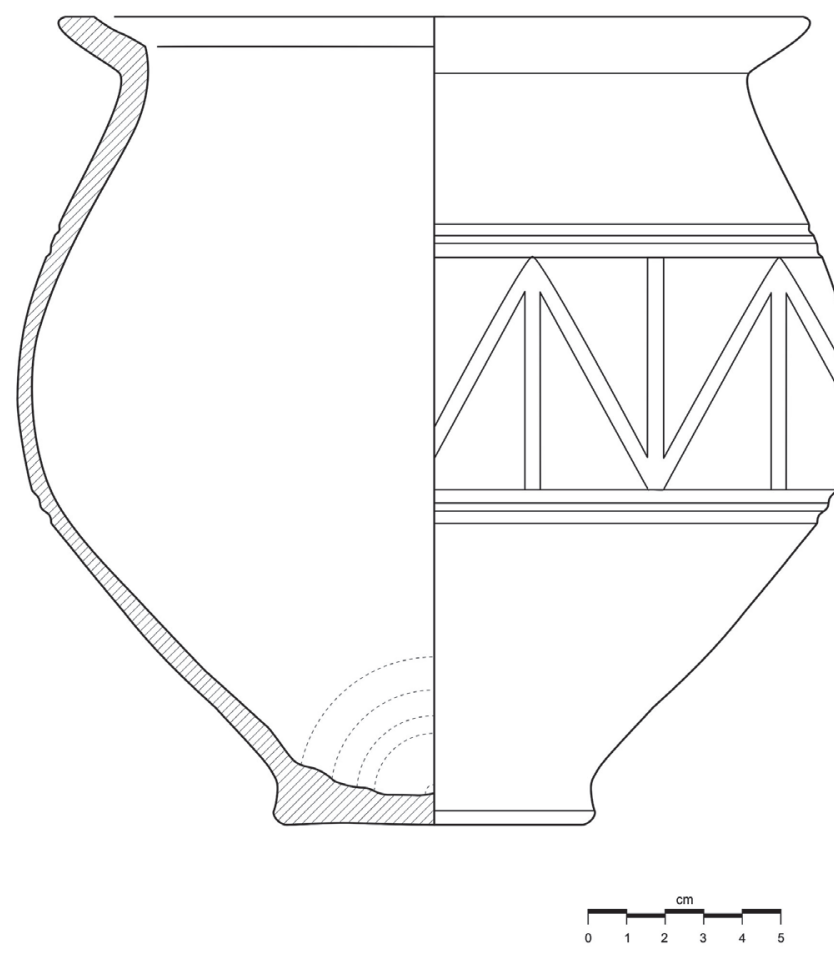

Figura 7. Grandes ollas globulares, grises, de borde exvasado y decoración espatulada. Tipo 012A.

\section{Morteros}

Para la campaña del 2007 contamos con un fragmento de mortero identificado, este se adscribiría dentro del tipo M3, morteros de cuerpo semiesférico, borde horizontal y piquera aplicada. Este fragmento (Fig.8.1) se caracteriza por poseer un borde horizontal liso sobre el cual se apoya el pico vertedor, formado por dos apliques de barro, uno a cada lado de la abertura. Presenta unas dimensiones para el borde en torno a los 30 y los $35 \mathrm{~cm}$ de diámetro. La pasta es ocre, con abundantes desgrasantes. El exterior presenta un tono ocre, un leve alisado y restos de quemado en la superficie. En consecuencia, la textura exterior es rugosa. Carece de decoración. Su función se adscribiría a la molturación, el 
mezclado y el rallado (ALCORTA IRASTORZA 2001: 312), utilizándose para el triturado de alimentos sólidos y para la preparación de salsas (DOVAL GALÁN, 1997: 290). Aunque nosotros desconocemos los datos que les permiten proponer otras funciones más allá de la de majar propiamente dicha.

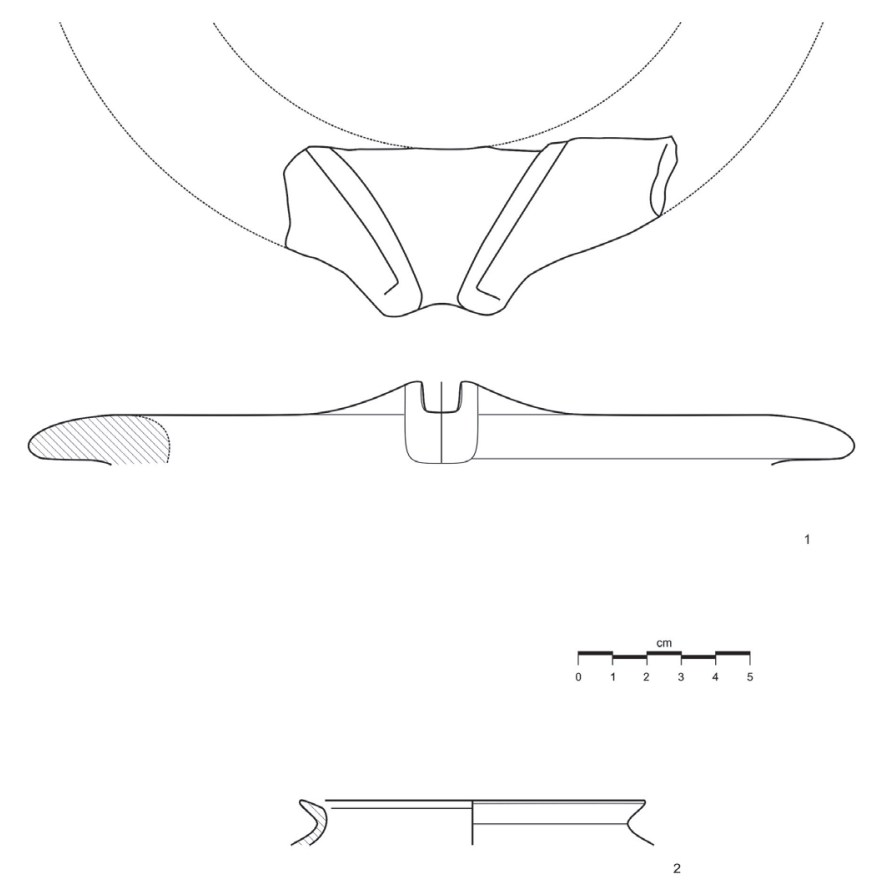

Figura 8. Morteros de cuerpo semiesférico, borde horizontal y piquera aplicada. Tipo M3 (1). Vasos ovoides de borde flexionado, sin decoración. Tipo V3 (2).

\section{Servicio de mesa}

\section{Vasos}

Se trata, en general, de piezas de escasa representatividad. Están caracterizados por poseer pequeñas dimensiones y buenos acabados, dotando a la pieza de un cuidado tratamiento superficial. Dentro de este apartado podríamos destacar el tipo $\mathrm{V}_{3}$ vasos ovoides de borde flexionado sin decoración. Para este tipo tendríamos un fragmento (Fig.8.2) caracterizado por presentar un borde exvasado triangular, de muy breve desarrollo, pero que presenta una aguda inflexión que marca el inicio del cuerpo. Este diseño lo hace inconfundible dentro de este tipo. Presenta además pastas grises, muy decantadas y con abundante mica, y una superficie externa bien alisada y suave al tacto. No tiene decoración.

\section{Jarras}

Aunque de escasa representación, los pocos fragmentos que conservamos de estos recipientes, han resultado ser muy significativos debido a su buen estado de conservación. Por un lado tendríamos el tipo J3, definido como jarras de cuerpo ovoide y reborde vertical, sin decoración. Nuestro fragmento (Fig.9.1) para este tipo presenta un diámetro de boca de $8 \mathrm{~cm} \mathrm{y}$, a pesar de que carece de reborde vertical, muestra un borde exvasado oblicuo, con un amplio desarrollo, y un arranque de cuerpo que parece ser 
ovoide. Presenta pastas grises, muy finas y con abundante mica. Su superficie exterior es del mismo tono y tiene un excelente acabado, constituyéndose como uno de los fragmentos de mejor calidad dentro de la colección del 2007, algo característico dentro de este tipo.

Dentro del apartado de las jarras, tenemos también el tipo EJ2, jarras engobadas, monoansadas, de borde acampanado, espatuladas. Respecto a las jarras este tipo sería el más representativo (Fig.9.2-3) para la campaña del 2007. En general, se trata de piezas formadas por un borde fuertemente exvasado (Fig. 9.3), labio apuntado y asas de sección plana. Todos los fragmentos presentan una concavidad en la cara interna del borde, posiblemente para una posible tapadera. Los diámetros oscilan entre los 6-7 cm para la apertura del borde. Las pastas son de color ocre, con desgrasantes muy finos de cuarzo y mica. Para la superficie externa, la totalidad de la muestra está recubierta mediante engobes de color rojo pompeyano. Carecen de decoración.

También cabría destacar el tipo J4, jarras monoansadas, groseras, de pico trilobulado cerrado, sin decoración. Dentro de este tipo nos encontramos con una pieza destacada

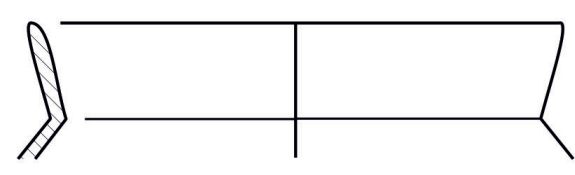

1
Figura 9. Jarras de cuerpo ovoide y reborde vertical, sin decoración. Tipo J3 (1). Jarras engobadas, monoansadas, de borde acampanado, espatuladas. Tipo EJ2 (2-3).
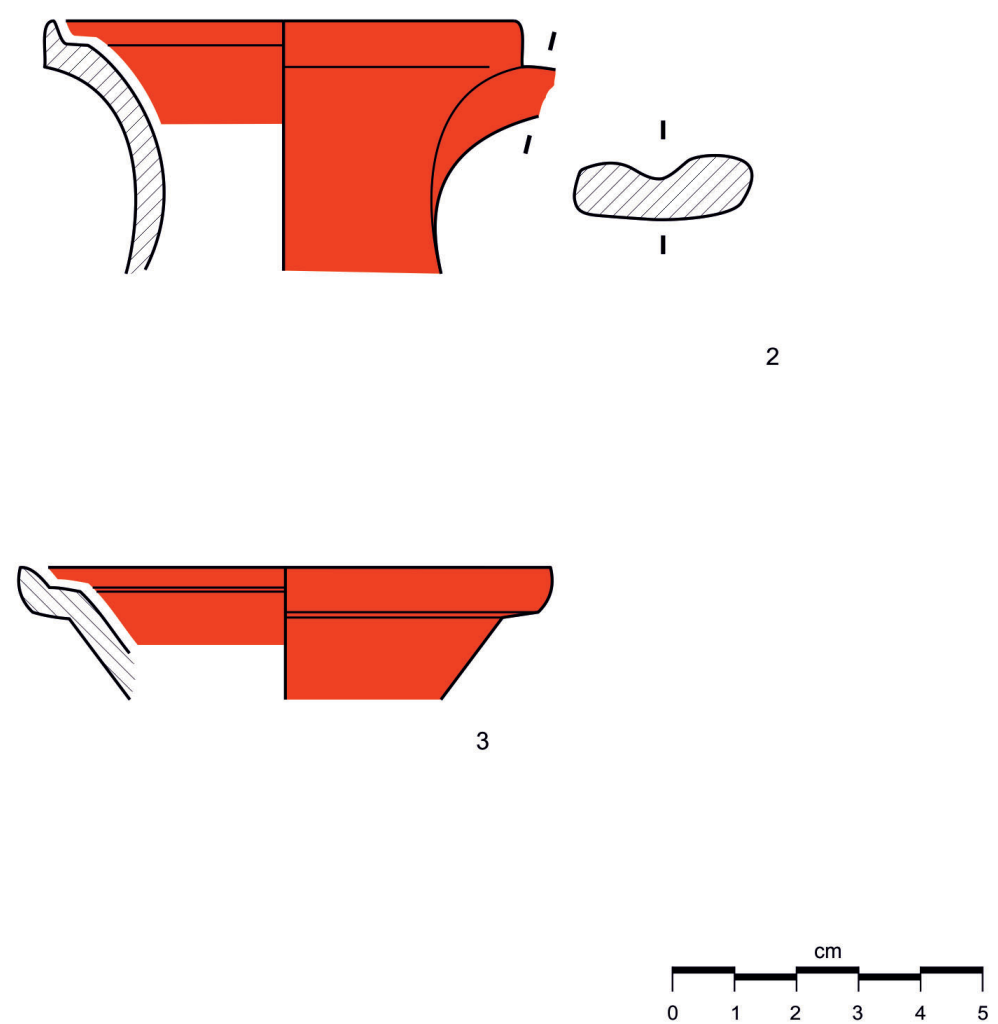
(Fig. 10) que, a pesar de encontrarse muy fragmentada nos muestra bastante bien las características principales que se definen para este tipo. Por un lado, nos encontramos con un fragmento formado por un cuello bastante estrecho y un asa de sección plana y posición vertical solapada al borde, presentando una acanaladura vertical. El borde se encuentra, en su mayoría, fragmentado y aunque ha sido imposible reintegrarlo en su totalidad, podemos afirmar que se trata de un borde trilobulado. Además este recipiente presenta una característica también común a este tipo de jarras, la presencia de un apéndice plástico en la parte superior, entre el borde y el asa, probablemente para colocar el dedo. Este fragmento se caracteriza también por presentar pastas grises y porosas, poco compactas y con abundantes desgrasantes de mica y cuarzo. También, coincidiendo plenamente con la definición tipológica, presenta una superficie de la misma gama tonal, escasamente tratada y rugosa al tacto debido a la presencia de desgrasantes en superficie. Solamente el borde tiene restos de alisado. Carece de decoración.

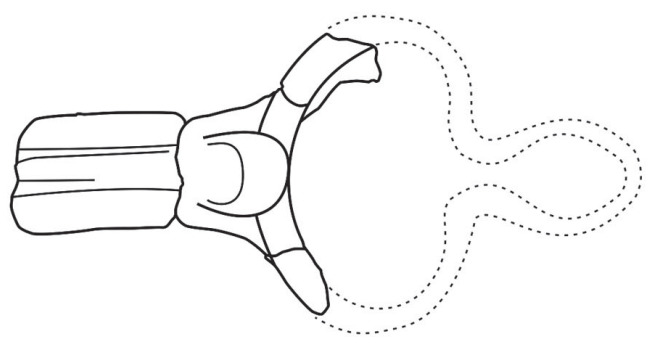

Figura 10. Jarras monoansadas, groseras, de pico trilobulado cerrado, sin decoración. Tipo J4 (4).

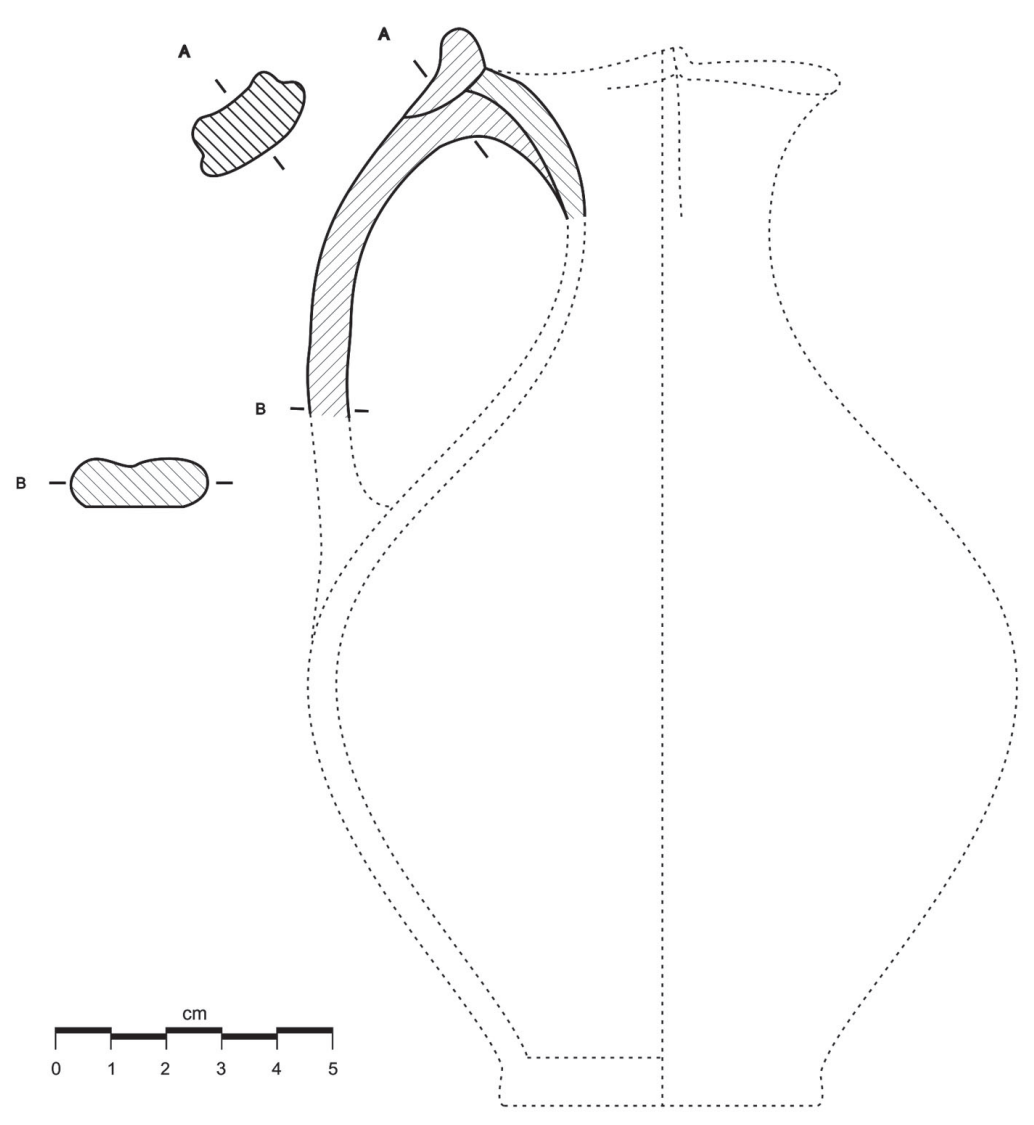




\section{Cuencos}

Tras las ollas, los cuencos son uno de los tipos mejor representados dentro de la colección del 2007, caracterizados por poseer un desarrollo semiesférico y apoyarse sobre fondos de disco. La mayor parte de la muestra se encuentra dentro de los tipos engobados.

En primer lugar habría que destacar el tipo EC1 (Fig. 11, 1-4), representativo dentro del grupo cerámico de 2007 y definido como cuencos semiesféricos engobados, de borde horizontal ranurado. Hemos podido comprobar en sus representaciones gráficas (ALCORTA IRASTORZA 2001:326) que el rasgo característico de los cuencos incluidos dentro del tipo EC1 es una ligera depresión o concavidad interna y nola ranura propiamente dicha a la que alude en su definición. Este problema de falta de correspondencia entre definición y dibujo es común en esta tipología.

Así pues nos encontramos en la campaña de 2007 con un grupo caracterizado por poseer o bien un borde horizontal ranurado (Fig. 11.1-2), o bien un borde horizontal cóncavo (Fig. 11.3-4) seguido de un cuerpo semiesférico y fondo plano. Las dimensiones oscilan entre los 17 y los $31 \mathrm{~cm}$ de apertura de borde. Uno de los recipientes (Fig.11.4) presenta una apertura de borde de $15 \mathrm{~cm}$, asemejándose a los tipos ES1, sin embargo, no coincide morfológicamente con estos cuencos engobados, que presentan un cuerpo

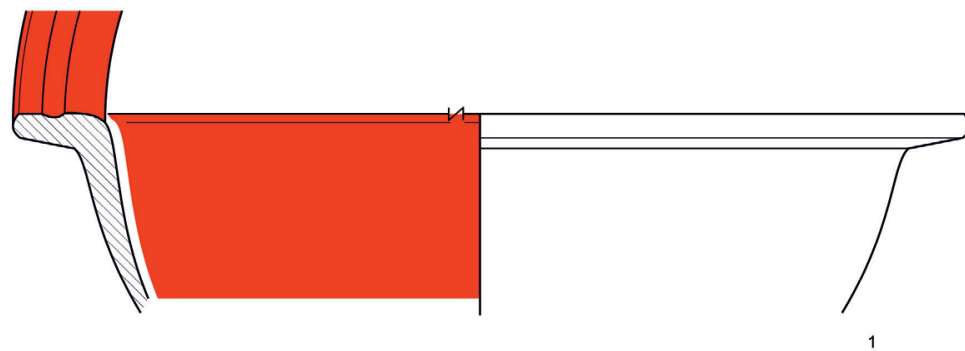

Figura 11. Cuencos semiesféricos engobados, de borde horizontal ranurado. Tipo EC1 (1-4).
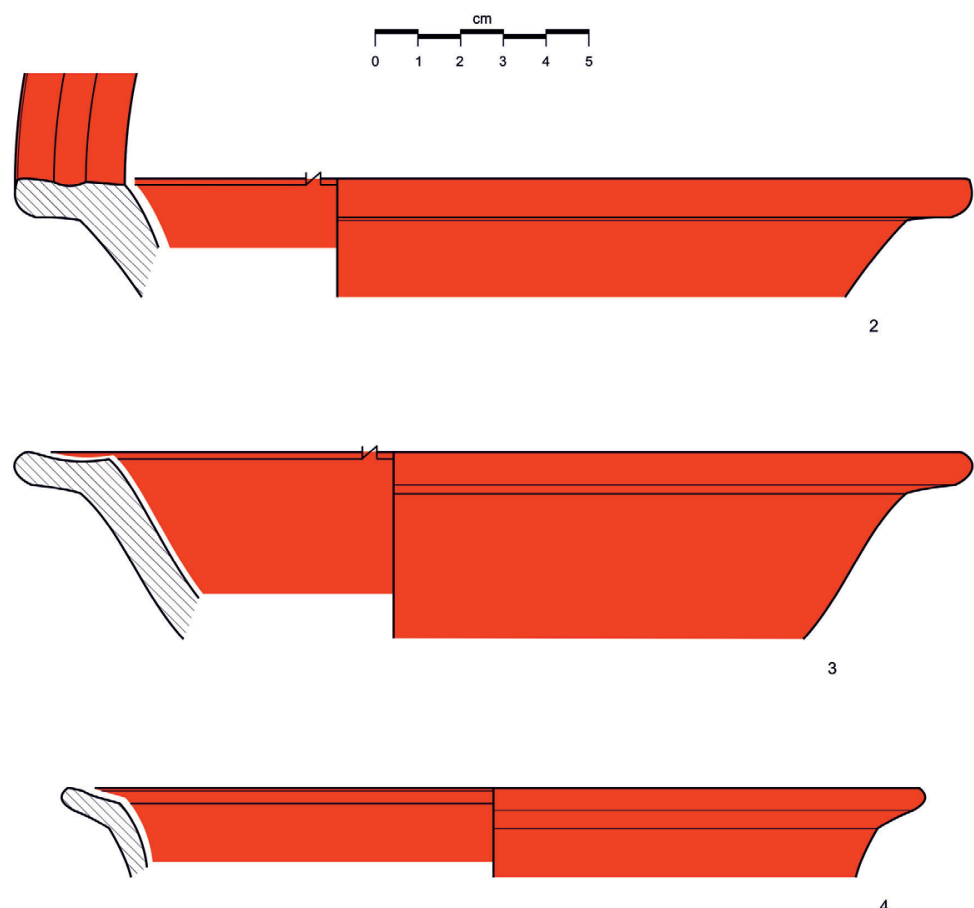
troncocónico y sellos. Respecto a las pastas, en general son ocres o naranjas, muy finas y depuradas y con aspecto laminado, predominando los desgrasantes pequeños de mica y cuarzo. En la superficie externa, presentan un característico engobe rojo pompeyano en ambas caras, salvo algunas excepciones (Fig.11.1)

Dentro de los cuencos tendríamos también el tipo C2 (Fig.12.1), cuencos de cuerpo carenado y borde engrosado de bastoncillo. Para este tipo, contamos dentro de la colección con un fragmento de cuenco que posee un borde engrosado y un cuerpo carenado caracterizado por un amplio desarrollo del sector basal perfectamente delimitado con la presencia de una acanaladura, bruñida posteriormente, que separa ambos sectores. Su diámetro es de $17 \mathrm{~cm}$ para la apertura del borde. La pasta es de color gris, fina, y con desgrasantes de mica y cuarzo. La superficie exterior es lisa, y está bien tratada, presentándose suave al tacto. Tiene un color grisáceo casi negro y no muestra signos de haber estado expuesta al fuego. Carece de decoración, a excepción de la acanaladura mencionada antes.
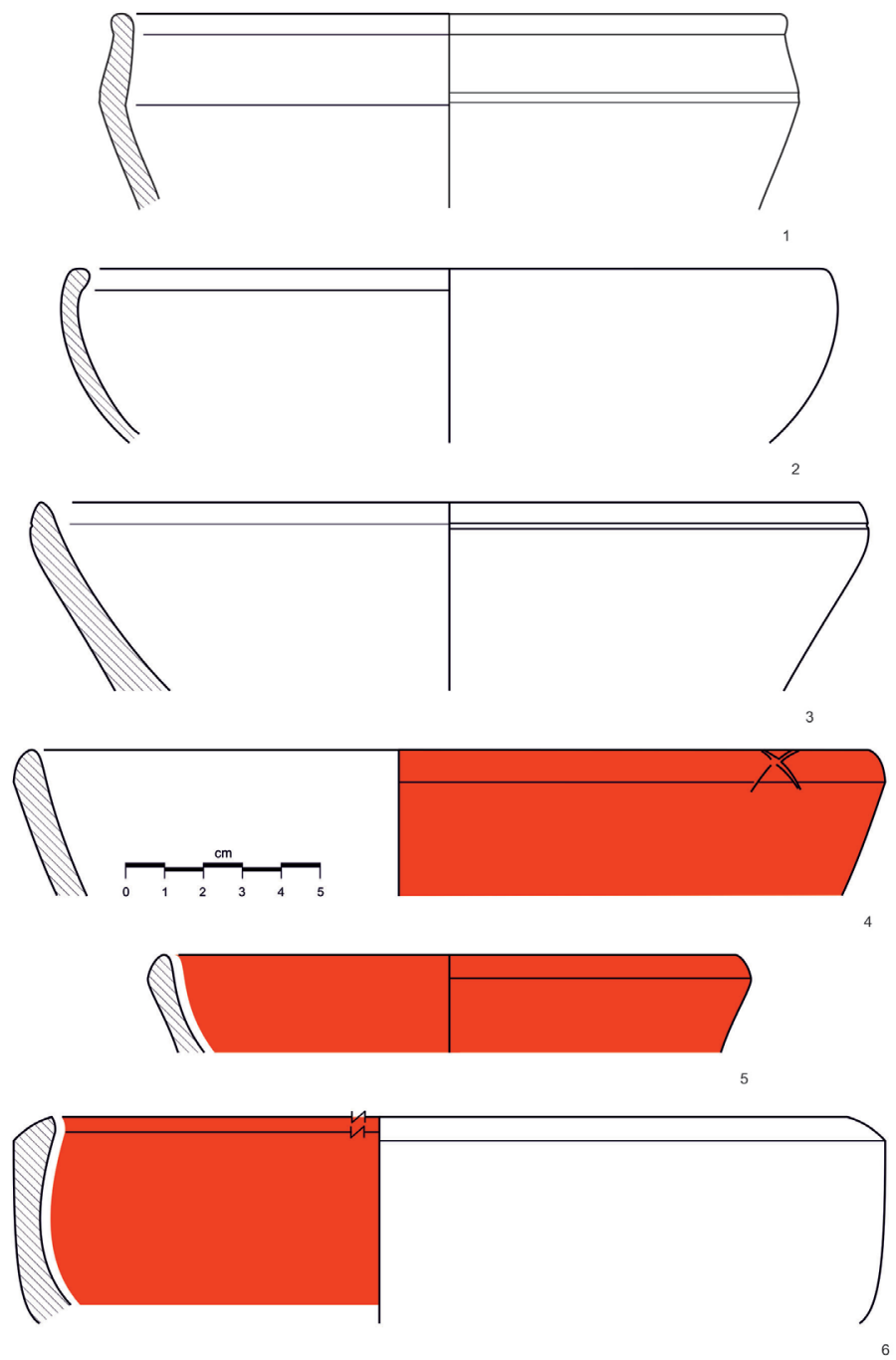

Figura 12. Cuencos de cuerpo carenado y borde engrosado de bastoncillo. Tipo C2 (1). Cuencos semiesféricos de borde engrosado. Tipo C3 (2). Platos grises de borde biselado, lisos. Tipo P1 (3). Platos engobados de borde biselado. Tipo EP1 (4). Platos engobados de borde biselado y pared rehundida. Tipo EP2 (5-6).

Por último tenemos el tipo $\mathrm{C}_{3}$ (Fig.12.2), los cuencos semiesféricos de borde engrosado. Para este esquema tenemos un fragmento que presenta un cuerpo semiesférico rematado en un borde no diferenciado ligeramente cerrado, que posee un pequeño engrosamiento 
hacia el interior. Su diámetro se encuentra sobre los $20 \mathrm{~cm}$ de apertura de borde. Las pastas son grises, con desgrasantes de mica y cuarzo. La superficie externa presenta un color gris con un correcto acabado. No tiene decoración.

\section{Platos}

Estos recipientes son escasos dentro de la colección del 2007, destacando solo 4 fragmentos susceptibles de ser identificados como platos, y predominando los engobados sobre los lisos. Sin embargo, sean engobados o no ambas variedades hacen un uso extraordinario, casi diríamos que exclusivo, de los bordes biselados. El resto de las características formales son generalmente idénticas para todos los casos.

Por un lado tendríamos el tipo P1 (Fig.12.3), los platos grises de borde biselado, lisos. Para este tipo, solo contaríamos con una pieza de borde biselado y cuerpo oblicuo, ligeramente rehundido en su cara interna. Su diámetro de boca se sitúa en los $20 \mathrm{~cm}$. Su pasta es de color gris, compacta, con desgrasantes de mica y cuarzo. Su superficie exterior coincide en color con las pastas, presentando un leve alisado por ambas caras. Parece conservar algunos restos de carbón y carece de decoración, salvo por la presencia de una línea incisa bajo el labio, remarcando el borde. Se trata de una pieza de elaboración fina.

El siguiente apartado se correspondería con el tipo EP1 (Fig.12.4), los platos engobados de borde biselado. Para este grupo contamos con un fragmento de plato de borde biselado con paredes oblicuas. Sus dimensiones son de $25 \mathrm{~cm}$ de diámetro para la boca. La pasta es ocre, fina y compacta, con desgrasantes de mica y cuarzo. La superficie exterior presenta la misma gama tonal, esta es suave, con engobe en la cara externa en la parte superior del borde, así como restos de carbón. La cara interna es rugosa, sin tratamiento aparente. Carece de decoración pero presenta, como característica diferenciadora, lo que parece ser un grafito, con forma de $\mathrm{X}$, en la parte superior del labio, del que hablaremos más adelante. Los ejemplares manchados de hollín, como en este caso, podrían emplearse como recipientes para la preparación de alimentos.

La última clasificación sería la del tipo EP2/EP2A (Fig.12, 5-6) los platos engobados de borde biselado y pared rehundida. Dentro de este tipo nos encontramos con grupos diferenciados en función de sus diámetros, por un lado, tendríamos un fragmento (Fig.12.5), con un diámetro de boca de unos $14 \mathrm{~cm}$ que se ajusta a lo establecido para el tipo EP2A, y que presenta una pasta gris, muy fina, con desgrasantes pequeños de mica; y por otro lado tendríamos un fragmento de plato (Fig.12.6) con un diámetro de boca de $26 \mathrm{~cm}$ que se encuadraría dentro del EP2, caracterizado por unas pastas negruzcas, finas, con desgrasantes de mica y cuarzo. Respecto a la superficie, ambos casos presentan engobado, -en el caso del tipo EP2 solo en la cara interna- y ambos muestran trazas de haber estado expuestas al fuego. Carecen de decoración.

\section{Otras formas}

Hemos reservado este apartado para todos aquellos fragmentos que, a pesar de presentar un buen desarrollo, no encajaban en la tipología de referencia. Por ello, hemos optado por analizarlos en un apartado distinto, dejando así constancia de su existencia y manteniendo este campo abierto para futuras investigaciones u ampliaciones. 


\section{Ollas}

Dentro de esta categoría entrarían los fragmentos de la Fig.13 (1-3). Para empezar tendríamos un fragmento de olla que presenta cuerpo globular y borde exvasado oblicuo, cóncavo en el interior (Fig.13.1). Sus dimensiones son de $20 \mathrm{~cm}$ para la apertura del borde. Se caracteriza por presentar unas pastas pardas, compactas y duras, con desgrasantes de mica y cuarzo. La superficie externa es negruzca y presenta un leve alisado. Tiene restos de carbón en su cara externa y carece de decoración. Esta pieza nos recuerda al tipo O15, sin embargo, difiere en dimensiones y pastas, así como en la composición del borde, curvo, frente a la horizontalidad de las O15. Tendría su equivalente en la forma genérica Tipo I de Vegas (1973: 11).

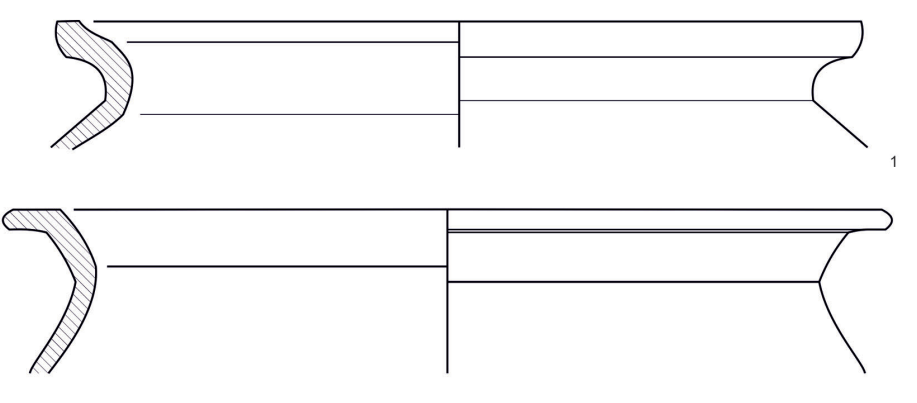

Figura 13. Otras formas. Ollas (1-3). Cuencos (4-6).
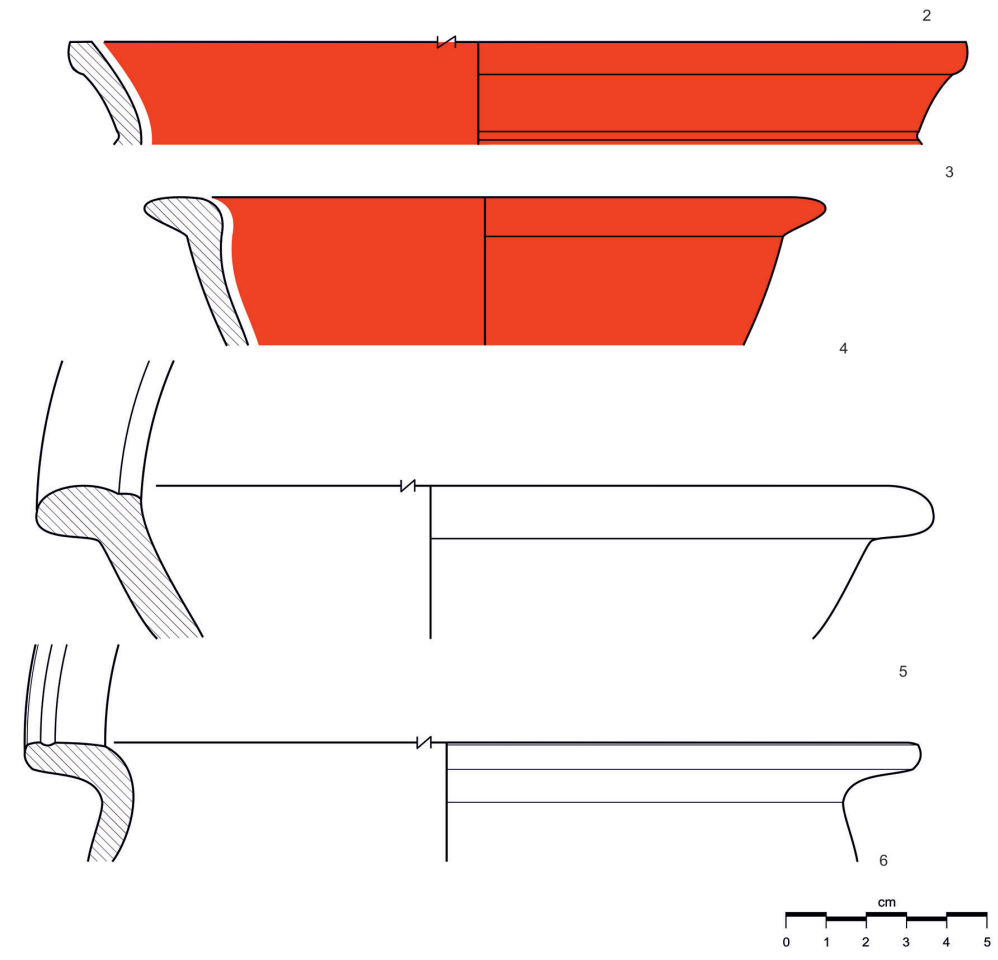

A continuación tendríamos una pieza caracterizada por presentar un borde exvasado con breve desarrollo horizontal (Fig.13.2). Este fragmento posee marcadas inflexiones y unos diámetros que presentan $19 \mathrm{~cm}$. para la apertura de borde. Presenta unas pastas toscas, de color ocre y un exterior no muy cuidado, de color grisáceo y con restos de alisado. En la tipología de referencia, solo encontramos este tipo de bordes en ollas grandes de almacenaje como las del tipo O12 o las del tipo O10, que difieren en dimensiones, y en 
morfología, ya que no presentan un desarrollo horizontal tan pronunciado ni marcadas inflexiones. Tenemos ollas similares, en gran número, en el yacimiento de Chao Samartín (Grandas de Salime, Asturias), en sus ollas lisas de borde exvasado (HEVIA GONZÁLEZ et al. 2000: 170)

Seguidamente, tenemos un fragmento de olla caracterizado por poseer un borde exvasado oblicuo con labio ligeramente engrosado hacia el exterior (Fig.13.3). Sus dimensiones para el borde son de $24 \mathrm{~cm}$ de diámetro. De pasta ocre, fina y bien decantada, micácea, presenta una superficie del mismo color, bien acabada, caracterizada por la presencia de engobe en ambas caras. Carece de decoración, exceptuando la línea espatulada en la parte inferior del cuello, remarcando la inflexión con el cuerpo. La única similitud que encontramos entre esta pieza y la tipología utilizada serían los tipos O14, las únicas ollas engobadas de la muestra, sin embargo, estos tipos se caracterizan por ser toscos, con una copiosa presencia de cuarzos de tamaño medio y una textura áspera, lo cual difiere claramente del ejemplo aquí presentado.

\section{Cuencos}

Dentro de esta categoría tendremos en un mismo apartado dos fragmentos (Fig. 13.45) caracterizados por poseer cuerpo semiesférico, borde horizontal acabado en labio apuntado en un caso y redondeado en el otro. Sus dimensiones son de $18 \mathrm{~cm}$ de apertura de borde para el primero y $25 \mathrm{~cm}$ para el segundo. El primero se caracteriza por presentar una pasta de un naranja muy fuerte, fina y bien decantada, con desgrasantes de mica y cuarzo. La superficie presenta la misma gama tonal, caracterizándose por presentar restos de engobe en la cara interna de la pieza y por mostrar la cara externa trazas de alisado. Carece de decoración. El segundo tiene pastas naranjas también, pero poco decantadas, con abundantes desgrasantes de mica y cuarzo. Carece de tratamiento superficial, conformando un recipiente tosco y áspero. Por sus características morfológicas podríamos incluir al primero dentro de los tipo EP4, Fuentes/Platos engobados de borde horizontal (ALCORTA IRASTORZA 2001: 350), sin embargo, la rareza de esta muestra, con su pasta naranja brillante frente a la ocre del tipo EP4, y sus reducidas dimensiones, provocan que no podamos afirmar plenamente esta tipificación. Para el segundo, cabría la posibilidad de incluirlo dentro de los $\mathrm{M}_{3}$, pero la ausencia de pico vertedor y sus reducidas dimensiones descartaron esta tipificación.

También tenemos un fragmento de borde horizontal con ranura y cuerpo globular (Fig.13.6). Sus dimensiones son de $23 \mathrm{~cm}$ para la apertura de boca. Se caracteriza una pasta ocre, porosa y compacta, con desgrasantes de mica y cuarzo. No presenta ningún tratamiento superficial, mostrándose la pieza tosca y áspera. Carece de decoración. Debido a su escaso desarrollo, no nos ha sido posible delimitar la categoría formal de este fragmento. De tratarse de un cuenco, este se asemejaría al tipo 4 de Vegas (1973:20), cuencos de borde horizontal, de similares características.

A continuación tendríamos un fragmento (Frag. 14.1) de cuenco de borde exvasado oblicuo, cóncavo en el interior, de grandes dimensiones: hasta $30 \mathrm{~cm}$ de apertura de borde. Está caracterizado por presentar pastas ocres, con desgrasantes de mica y cuarzo. $\mathrm{Su}$ cara externa es de la misma gama tonal y presenta restos de alisado. Carece de 
decoración. Por sus características morfológicas podría ser incluido dentro de los EC1, pero, su falta de engobe no nos permite adscribirlo a este tipo.

Por otro lado tendríamos un fragmento de cuerpo de posible cuenco de borde exvasado oblicuo con labio triangular (Frag.14.2). Su diámetro para la boca se sitúa en torno a los $16 \mathrm{~cm}$. Está caracterizado por presentar pastas grises, finas y micáceas en consonancia con la superficie externa, del mismo color y bien alisada y suave al tacto. Carece de decoración. Este fragmento es único dentro de la muestra analizada y, por sus características formales, no ha sido posible enmarcarlo dentro de ningún tipo en concreto. Estaría próximo a los $\mathrm{C}_{3}$ ya que presenta trazas de un posible cuerpo semiesférico y coincide en las pastas, también grises finas, y los acabados, cuidados, pero la rareza de su labio triangular lo acerca a las cerámicas grises tardías tipo GT3 (ALCORTA IRASTORZA 2001: 386), con formas similares y al plato de borde engrosado, tipo Nov.16, recogido por Beltrán (1990:205), aunque ambas tendrían mayores dimensiones.

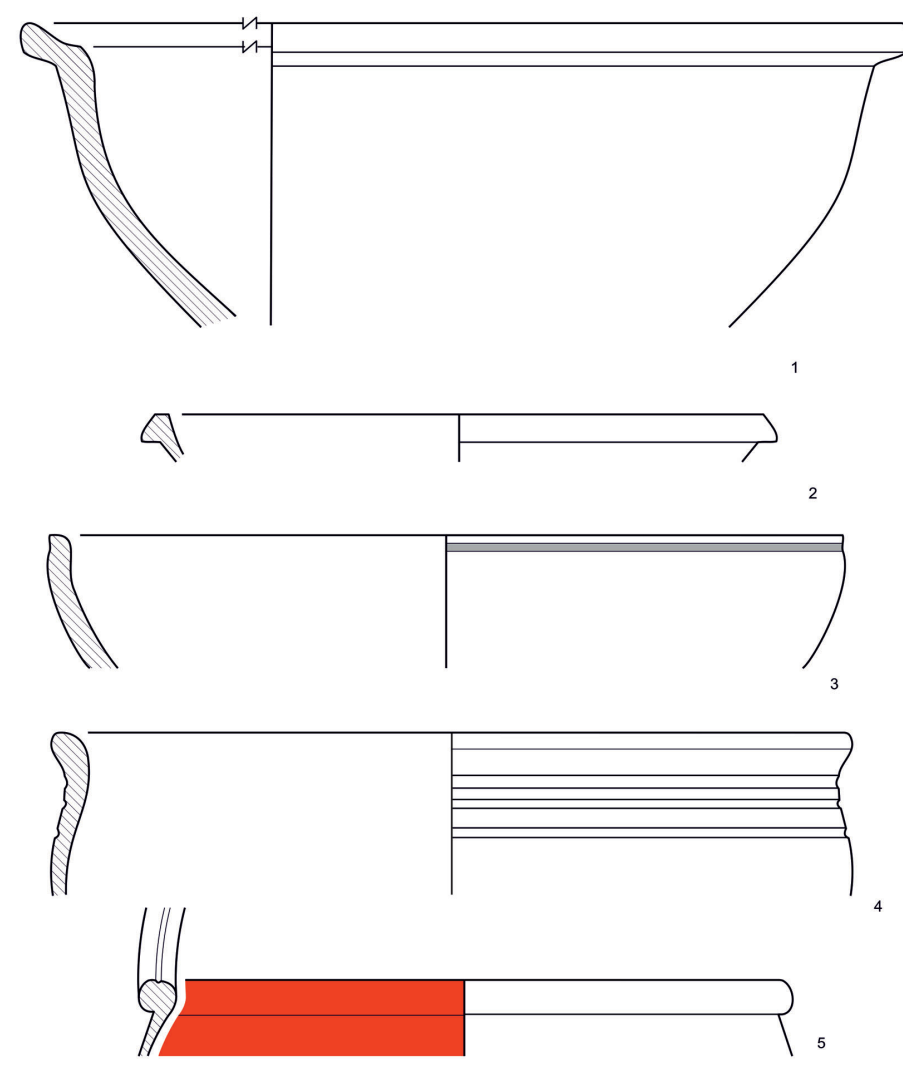

Figura 14. Otras formas. Cuencos (1-6).

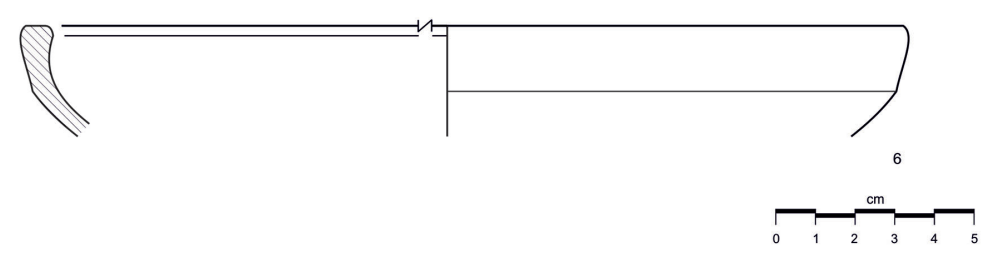

El siguiente fragmento (Fig.14.3) estaría caracterizado por poseer un cuerpo semiesférico que termina en un borde no diferenciado ligeramente cerrado. Su diámetro es de $20 \mathrm{~cm}$. para la apertura de borde. La pasta es gris, con desgrasantes de mica y cuarzo. La superficie externa presenta colores grises y marrones con correctos acabados. 
No presenta decoración a excepción de una acanaladura que recorre la parte inferior del labio. Este fragmento se podría inscribir dentro del tipo $\mathrm{C}_{3}$, pero sus acusadas diferencias morfológicas no nos lo permiten.

Por último tenemos una serie de fragmentos (Fig.14.4-6) a los que no hemos logrado adscribir semejanza o paralelismo alguno. Se trata de un fragmento (Fig.14.4) de cuenco con borde ligeramente exvasado y engrosado, cuerpo globular y decoración formada en base a un trio de acanaladuras situadas en la parte superior de la pieza. Presenta pastas negras y micáceas, cara externa del mismo color y con trazas de alisado. Tiene un diámetro de $20 \mathrm{~cm}$. para la apertura de borde. Seguidamente destacaríamos un fragmento de cuenco engobado (Fig.14.5) caracterizado por poseer un borde fuertemente engrosado que presenta una marcada incisión en la parte superior del labio. Sus pastas son finas, de color ocre anaranjado, igual que la cara externa de la pieza, que está alisada y muestra una buena factura. Está engobado en su cara interna y presenta un diámetro de $16 \mathrm{~cm}$. A continuación tendríamos un fragmento (Fig.14.6) de cuenco carenado con borde ligeramente engrosado que finaliza en un labio recto. Su diámetro de borde es de $23 \mathrm{~cm}$. Presenta pastas de color gris, finas y con desgrasantes de mica y cuarzo. La superficie exterior es lisa, y está bien tratada, siendo suave al tacto. Presenta un color grisáceo casi negro y no muestra signos de haber estado expuesta al fuego. Carece de decoración.

\section{Jarras}

Tendríamos en este grupo un fragmento de jarra de borde vertical, embocadura estrecha, borde en L y asa acodada de sección aplanada, con rehundimiento longitudinal (Fig.15.1). Su apertura de borde ronda los 3-4 cm de diámetro. La pasta es ocre, micácea y fina. La superficie externa, de la misma gama tonal, se encuentra deteriorada, presentando una textura rugosa sin tratamiento superficial. Carece de decoración. Esta pieza presenta grandes similitudes tanto formales, como de pastas, con el tipo EJ1, las jarras engobadas de amplia y estrecha embocadura con borde en "L" y asa acodada de sección aplanada sin rehundimiento longitudinal (ALCORTA IRASTORZA 2001: 294). Sin embargo, la ausencia de engobe, presente en EJ1, nos hace imposible adscribirla dentro de este grupo.

A continuación tendríamos un fragmento de jarra de perfil sinuoso y borde con ranura (Fig.15.2). Esta pieza presenta un leve borde exvasado, con ranura interna y cuerpo sinuoso. Sus dimensiones son de $19 \mathrm{~cm}$ para la apertura del borde. Posee unas pastas de color pardo, con desgrasantes de mica y cuarzo. La superficie externa es de color ocre y tiene un buen alisado. Está totalmente regularizada, y carece de decoración. Este fragmento resulta muy similar, morfológicamente, al tipo delimitado como J1, las jarras monoansadas de perfil sinuoso y decoración combinada (ALCORTA IRASTORZA, 2001:271). Coincide en cuanto a pastas y diámetros, sin embargo carece de asa, decoración y el borde es cóncavo en su cara interna. Para este fragmento, hemos encontrado paralelos dentro de la cerámica común romana del campamento romano de Rosinos de Vidriales (Zamora), observando similitudes en sus jarras de boca ancha, caracterizadas por poseer borde simple, ligeramente exvasado y ocasionalmente cóncavo en el interior, cuello sin diferenciar, asa de sección plana y acanaladuras y perfil sinuoso (Carretero Vaquero, 2000: 680). Coincide además, en pastas y dimensiones. 


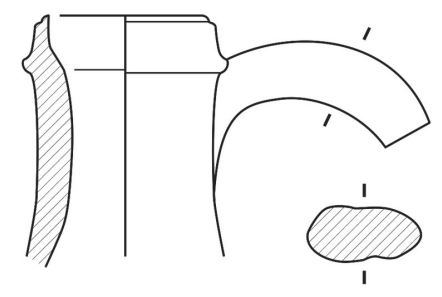

Figura 15. Otras formas. Jarras (1-2). Plato (3). Indeterminada (4).
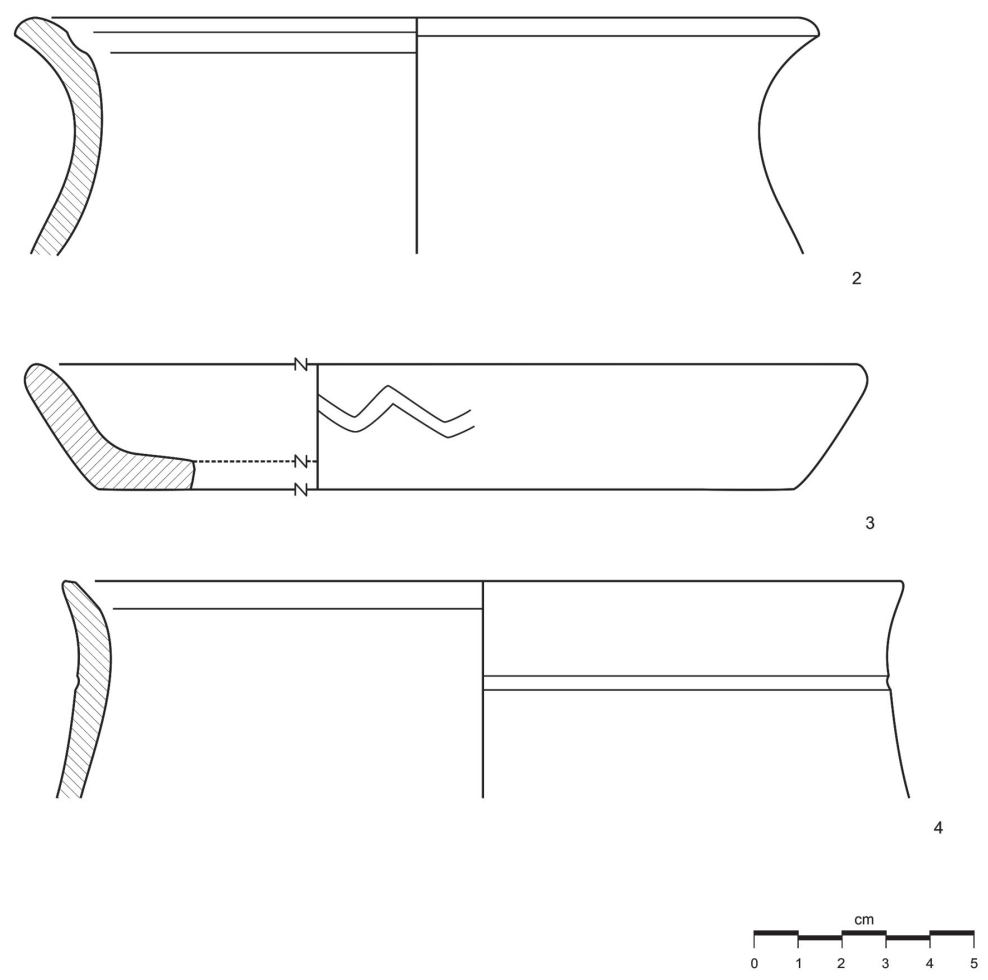

\section{Platos}

Pieza caracterizada por presentar un fondo plano, cuerpo oblicuo y borde redondeado (Fig.15.3). Aparentemente presenta el perfil completo. Sus dimensiones oscilan en torno a los $25 \mathrm{~cm}$ para la apertura del borde. Presenta pastas ocres y finas, con desgrasantes de mica y cuarzo. La superficie es ocre también y presenta un leve tratamiento superficial en forma de alisado. Está decorada en la cara externa con una única línea incisa ondulada, situada en la parte media. No hemos encontrado ningún paralelo en la tipología manejada para esta pieza que, por otro lado, es única dentro de la muestra analizada. Podríamos incluirla dentro del tipo PV de Alcorta (2001:362), conformado por un grupo de piezas únicas, que presentan características similares en cuanto a pastas, morfología y dimensiones.

Por último tendríamos un fragmento difícil de determinar (Fig.15.4) por el escaso desarrollo de su perfil, que nos muestra un cuerpo casi recto, con una pequeña inflexión para marcar el borde, que está ligeramente exvasado y que presenta un labio redondeado. Tiene una línea horizontal bruñida bajo el borde, y su diámetro es de $19 \mathrm{~cm}$. de apertura de boca. Sus pastas son grises, con desgrasantes de mica y cuarzo. La superficie externa es del mismo color, mostrándose alisada. Salvo la línea mencionada antes, carece de decoración. 


\section{Grafitos}

Constatamos para esta campaña del 2007 la presencia de dos fragmentos con grafito. Por un lado tenemos una inscripción representada sobre un fragmento de panza (Fig. 16.1), indeterminado, caracterizado por poseer pastas grises, decantadas, de buena calidad, superficie del mismo color con acabado excelente, y la presencia de dos acanaladuras situadas sobre la inscripción [...] VI RI [...].La segunda inscripción (Fig. 16.2) se presenta sobre un fragmento de panza también, pero este de inferior calidad, con pastas color ocre, superficie del mismo color, aparentemente sin tratamiento, y con signos de haber estado expuesta al fuego. Esta presenta una inscripción de difícil interpretación.

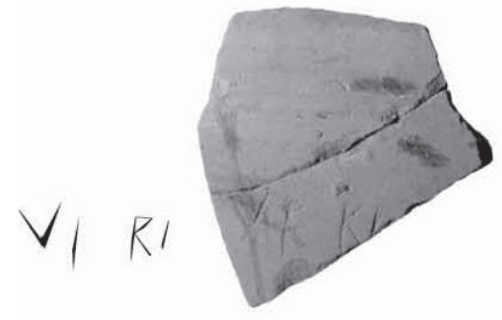

1
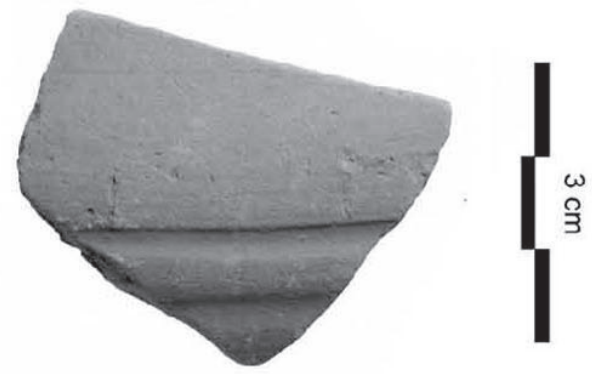

3

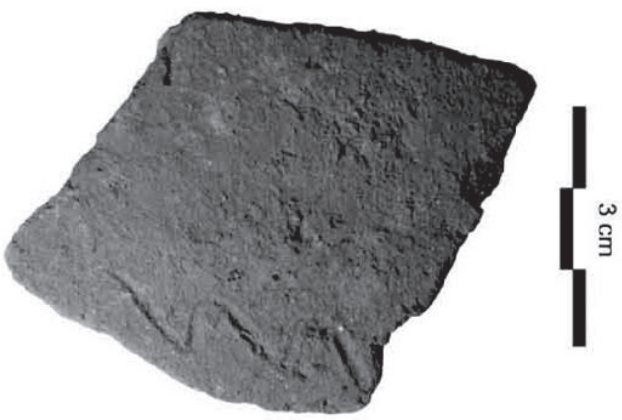

5

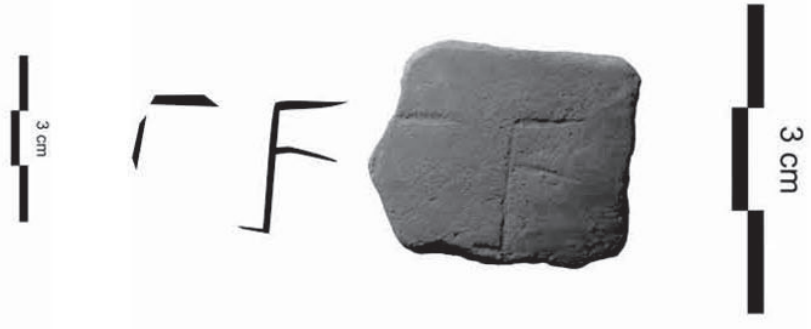

2

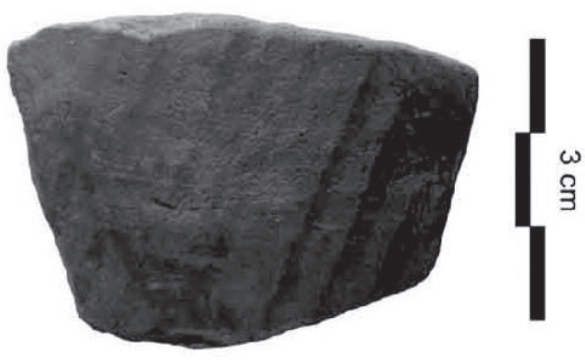

4

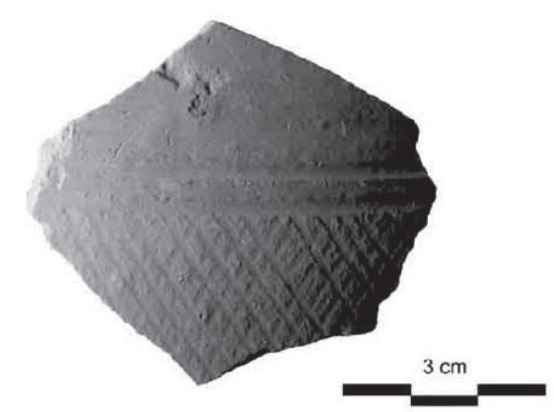

6

Figura 16. Fragmentos con grafito (1-2). Fragmentos con decoración (3-6). 
Siguiendo a Alcorta (2001: 393) que, para la cerámica común romana con grafitos establece cuatro grandes grupos, estos dos ejemplos podrían enmarcarse o bien dentro del grupo de los nominales, o bien dentro del grupo de los literales. Los nominales indican, generalmente mediante antropónimos latinos, el nombre del propietario de la vasija. Suelen trazarse de forma visible, preferentemente en el hombro o en el sector superior de la panza. Los grafitos nominales apenas se constatan en recipientes de cocina o almacenaje siendo frecuentes, sin embargo, en vasijas finas pertenecientes al servicio de mesa. Entendemos por grafitos literales expresiones de variada longitud que abordan los más diversos aspectos de la actividad cotidiana. Dada la escasa representación de estos fragmentos, y su difícil interpretación, creemos que se pueden enmarcar, indistintamente, dentro de cualquiera de estos dos grupos.

También cabría destacar aquí el fragmento de plato tipo EP1 con posible grafito (Fig.12.4), ya mencionado anteriormente. Esta supuesta inscripción, podría enmarcarse dentro del grupo de los grafitos aspados o cruciformes muy abundantes y que casi siempre aparecen grabados sobre los fondos, ocultos a la vista, o inscritos de manera preferente sobre piezas finas, en especial sobre plataformas de vasos finos, así como en recipientes engobados. La correcta comprensión de estos grafitos tardíos no está exenta de problemas, sosteniendo algunos investigadores que podrían tratarse de simples marcas o anagramas de posesión.

\section{Decoración}

Como hemos podido comprobar a lo largo de este estudio, la decoración en cerámica común romana se trata de algo aislado y marginal. Entre los escasos temas decorativos que hemos podido encontrar dentro de este grupo cerámico, destacarían por su número los espatulados (Fig. 16.3), normalmente presentados mediante una sucesión de líneas horizontales y presentes especialmente en fragmentos de buena calidad, con excelentes acabados. También tendríamos que destacar, aunque en menor medida, la presencia de bruñidos (Fig. 16.4), dispuestos horizontalmente o en forma de retícula, presentes en fragmentos de pastas grises y ocres, con superficies oscuras aparentemente alisadas. La presencia de líneas incisas es abundante también (Fig. 16.5) pudiendo aparecer marcando la zona de inflexión entre el borde y el cuello, aisladas a modo decorativo como es el caso, o apareciendo, excepcionalmente, cercanas a la base. La decoración también puede aparecer variada, formada por una doble línea horizontal espatulada, bajo la que se puede ver una retícula formada por líneas con un bruñido profundo (Fig. 16.6).

Así pues, aunque ocasionalmente hemos encontrado piezas profusamente decoradas, como es el caso de nuestra olla tipo O12A (Fig.7) descrita anteriormente, o el caso del plato con decoración ondulada que hemos presentado en el apartado de tipos no identificados (Fig. 15.3) estos ejemplos poseen un carácter marginal dentro de la muestra. Por lo general, la cerámica común romana estará caracterizada por su simplicidad decorativa, primando la funcionalidad sobre la estética. 


\section{Conclusiones}

Hemos podido observar cómo dentro de la muestra analizada los recipientes de cocina aparecen con mayor representatividad que los de mesa. Este alto número de materiales de cocina contribuye a corroborar la idea de que las estructuras de las que procede la cerámica estudiada no son de almacenamiento tipo Horrea, tal y como se propuso inicialmente. Además, el escaso número de recipientes de mesa podría indicarnos una posible complementación con los tipos de terra sigillata, presentes en gran número dentro del campamento.

Respecto al servicio de cocina, destacan en número las ollas y, dentro de estas, la olla O1 como el tipo más abundante, seguido de cerca por el O2. También hay que mencionar las ollas grandes de almacenaje (tipo O6). Esta predominancia debe ser matizada, ya que en la tipología empleada estos tipos (O1 y O2) abarcan una amplia variabilidad formal que permite la adscripción de la mayoría de los fragmentos dentro de ellos. Sin embargo no se puede negar que la presencia de ollas globulares de borde exvasado oblicuo y curvo es alta, tanto en este yacimiento como en otros similares.

En cuanto a los recipientes de mesa estos estarán caracterizados, en su mayoría, por la calidad de su elaboración, lo cuidado de los tratamientos exteriores y la ausencia de manchas externas de exposición al fuego, como es el caso de los cuencos tipo EC1, las jarras tipo EJ2 y los platos tipo EP2, todos tipos engobados.

Respecto a la tecnología de esta cerámica, en líneas generales tratamos con una colección que presenta una gran homogeneidad en cuanto a técnica, pastas y tratamiento. La gran mayoría de las cerámicas son de cocción reductora y están fabricadas a torno. En los fragmentos en los que no hemos podido identificar está técnica, se debe, en general, a su alto grado de deterioro. Los acabados suelen aparecer en forma de alisados, siendo casi inexistentes los bruñidos y predominando los engobes para el servicio de mesa.

Como hemos visto anteriormente, la decoración no es muy abundante. Esta sobriedad es algo habitual dentro de la cerámica común romana, donde lo práctico parece estar por encima de lo estético.

Así pues vemos como el análisis tipológico muestra una estandarización en la producción en base a una serie de tipos que se repiten a lo largo de toda la muestra. Desde un punto de vista macroscópico, estos tipos presentan cierta similitud, tanto formal como tecnológica, con las cerámicas de los alfares lucenses. Ello refuerza la idea de una posible relación con la ciudad, aunque el carácter preliminar de este estudio no nos permite situar el origen de la cerámica común romana de Cidadela en los alfares de Lugo. El estudio futuro de otras colecciones procedentes del campamento, así como la ejecución de análisis mineralógicos en la muestra puede ayudarnos a arrojar nuevos datos sobre esta relación.

Por otra parte, aunque la cerámica común no es un gran indicador cronológico, cabe mencionar que no hemos encontrado en nuestra muestra elementos discrepantes con la cronología propuesta para el yacimiento.

A la luz de nuestros resultados, consideramos conveniente realizar una revisión de esta metodología, matizando las descripciones de algunos de sus tipos, que resultan 
ambiguas, vagas o confusas, aunque nos sigue pareciendo un método apropiado para el estudio del resto del yacimiento.

Esperamos que la progresión de estos trabajos contribuya a mejorar nuestro conocimiento sobre el asentamiento y sus estructuras, esclarecer la procedencia de la cerámica y establecer hipótesis acerca de las posibles relaciones comerciales y de abastecimiento del campamento para, en última instancia, ampliar nuestra comprensión de la Galicia romana en todos sus ámbitos.

Por último, queremos agradecer a Enrique Alcorta la ayuda prestada para realizar la correcta determinación de los tipos y al personal del Museo Arqueolóxico e Histórico "Castelo de San Antón" por la calurosa acogida que nos brindaron. También agradecemos las aportaciones y sugerencias de dos de los tres revisores.

\section{Bibliografía}

ALCORTA IRASTORZA, E. 2001. Cerámica común romana de cocina y mesa hallada en las excavaciones de la ciudad. Lugo.

BARTOLOMÉ ABRAIRA, R. 2008. "Primeiras valoracións da intervención realizada en Agra dos Castros, Marcelle (Lugo)". CROA, Boletín da Asociación de Amigos do Museo do Castro de Viladonga, 18, pp. 28-33.

BELTRÁN, LLORIS M. 1990. Guía de la cerámica romana. Zaragoza.

CAAMAÑO GESTO, J.M. 1984. "Excavaciones en el campamento romano de Cidadela (Sobrado dos Monxes. Coruña). Memoria preliminar de la campaña de 1981". Noticiario Arqueológico Hispano, 18, pp. 233-254.

CAAMAÑO GESTO, J.M. 1990. "Vidrios hallados en el campamento de Cidadela (Sobrado dos Monxes - A Coruña)". Gallaecia, 12, pp. 177-190.

CAAMAÑO GESTO, J.M, CASTRO PAREDES, I., ÍNSUA LIÑARES, M.J., LÓPEZ PÉREZ, M.C., VÁZQUEZ MARTÍNEZ, M. A.; FERNÁNDEZ RODRÍGUEZ, C. 200o. "Evidencias materiales en el campamento romano de Cidadela "Sobrado dos Monxes, A Coruña-". V. Oliveira Jorge (Ed.), Arqueología da Antigüedade na Península Ibérica, Actas do $3^{o}$ Congresso de Arqueología Peninsular (Vila Real, 1999). Porto, pp. 281-292.

CAAMAÑO GESTO, J. M.; FERNÁNDEZ RODRÍGUEZ, C. 2002. "Excavaciones en el campamento de Cidadela (A Coruña)". Brigantium, 12, pp.199-207.

CARLSSON-BRANDT FONTÁN, E. 2011. "El material constructivo latericio en el campamento de Cidadela (Sobrado dos Monxes, A Coruña)". Gallaecia, 30, pp.167-180.

CARRETERO VAQUERO, S. 2000. El campamento romano del Ala II Flavia en Rosinos de Vidriales (Zamora). La Cerámica. Zamora.

COSTA GARCÍA, J.M. 2013. Arqueología de los asentamientos militares romanos en la Hispania altoimperial (27 a. C. - ca. 280 d.C.). Tesis Doctoral Inédita, Universidad de Santiago de Compostela.

DOVAL GALÁN, J.F. 1990. Cerámica común romana del Campamento de Cidadela, Tesis de licenciatura inédita, Universidad de Santiago de Compostela.

DOVAL GALÁN, J. F. 1997. "Los morteros del campamento de Cidadela". Gallaecia, 16, pp. 285-300. GARCÍA ROMERO, C. 1909a. "Las lápidas romanas de Ciudadela". Boletín de la Real Academia Gallega, III, pp. 147-149.

HEVIA GONZÁLEZ, S., MONTES LÓPEZ, R., BENÉITEZ GONZÁLEZ, C. 200o. "Cerámica común romana del Chao Samartín (Grandas de Salime-Asturias). Vajilla de cocina y almacenamiento". Boletín del Seminario de Arte y Arqueología, 66, pp. 153-196. 
HUGUET ENGUITA, E. 2013). "El material más usado por los antiguos. La cerámica común y de cocina". A. Ribera i Lacomba (Coord.), Manual de cerámica romana del mundo helenístico al Imperio Romano. Madrid, pp. 291-330.

LÓPEZ PÉREZ, M.C. 2006. "La importación de terra sigillata en el campamento de Cidadela (Sobrado dos Monxes, A Coruña)". Á. Morillo Cerdán (Ed.), Arqueología militar romana en Hispania II: Producción y abastecimiento en el ámbito militar. León, pp. 432-437.

LÓPEZ PÉREZ, M.C.; CAAMAÑO GESTO, J.M. 2011. "La cerámica de paredes finas del campamento romano de Cidadela (Sobrado dos Monxes, A Coruña)". Gallaecia, 31, pp. 134-144.

RAMIL GONZÁLEZ, E. 2007. Excavación arqueolóxia e consolidación no campamento romano de Cidadela. Sobrado dos Monxes. Memoria técnica. Inédita.

RAMIL GONZÁLEZ, E., COSTA GARCÍA, J.M., CAAMAÑO GESTO, J.M. 2013. "Hornos hallados en el campamento romano de Cidadela (Sobrado dos Monxes, A Coruña)". Boletín del seminario de estudios de arte y arqueología, pp.269-290.

SEECK, O. 1876. Notitia Dignitatum accedunt notitia urbis Constantinopo1itanae et 1atercu1a Provinciarumo. Frankfurt.

VAZQUEZ MARTÍNEZ, M.A. 200o. Los vidrios de Cidadela (Sobrado dos Monxes, A Coruña). Memoria de Licenciatura. Universidad de Santiago de Compostela.

VEGAS, M. 1973. Cerámica común romana del Mediterráneo Occidental. Barcelona. 